\title{
ipen
}

INSTITUTO DE PESQUISAS ENERGÉTICAS E NUCLEARES

Autarquia Associada à Universidade de São Paulo

\section{LEVANTAMENTO DA ENTOMOFAUNA DE PLANTAS MEDICINAIS, AROMÁTICAS E CONDIMENTARES E DESINFESTAÇÃO PELO PROCESSO DE IRRADIAÇÃO}

\author{
Dissertação apresentada como \\ parte dos requisitos para \\ obtenção do Grau de Mestre em \\ Ciências na Área de Tecnologia \\ Nuclear - Aplicações.
}

Aluno: Fabrício Caldeira Reis

Orientador: Prof. Dr. Valter Arthur

São Paulo 
INSTITUTO DE PESQUISAS ENERGÉTICAS E NUCLEARES

Autarquia Associada à Universidade de São Paulo

\title{
LEVANTAMENTO DA ENTOMOFAUNA DE PLANTAS MEDICINAIS, AROMÁTICAS E CONDIMENTARES E DESINFESTAÇÃO PELO PROCESSO DE IRRADIAÇÃO
}

\author{
Dissertação apresentada como \\ parte dos requisitos para \\ obtenção do Grau de Mestre em \\ Ciências na Área de Tecnologia \\ Nuclear - Aplicações.
}

Aluno: Fabrício Caldeira Reis

Orientador: Prof. Dr. Valter Arthur

São Paulo 


\section{Dedicatória}

Aos meus pais Geraldo Robinson dos Reis e Maria Beatriz Caldeira Reis exemplo de dignidade como pessoa humana e por todo apoio oferecido ao longo da minha vida. 


\section{AGRADECIMENTOS}

Ao Prof. Dr. Valter Arthur do Centro de Energia Nuclear na Agricultura CENA/USP, pela oportunidade, orientação e confiança depositada.

Ao Pesquisador Dr. Marcos Roberto Potenza, do Instituto Biológico IB/SP, por todos os ensinamentos profissionais e suporte técnico. Fundamental para minha formação acadêmica desde os tempos da graduação.

A Coordenação de Aperfeiçoamento de Pessoal Nível Superior - CAPES pela bolsa concedida.

Ao Instituto Biológico - IB/SP por permitir a realização dos experimentos.

Ao Instituto de Pesquisas Energéticas e Nucleares IPEN/CENEN pela oportunidade de realização do curso de mestrado.

A Prof. Dra. Simone Aquino, a quem muito admiro, por ter dedicado seu precioso tempo na elaboração das metodologias aplicadas neste trabalho, acreditando em mim, pela nossa amizade e respeito.

Ao Dr. Pablo Antonio Vásquez Salvador (Coordenador do Irradiador Multiproposito-60Co) pela irradiação dos materiais e sugestões que vieram a enriquecer este trabalho.

Ao Técnico Agrícola do Instituto Biológico IB/SP Edvaldo José de Almeida por todo confiança, auxilio, dedicação e principalmente amizade.

A toda equipe do Laboratório de Pragas em Horticultura IB/APTA pelo apoio e companheirismo. 
"Há um prazer nas florestas desconhecidas; Um entusiasmo na costa solitária; Uma sociedade onde ninguém penetra; Pelo mar profundo e música em seu rugir; Amo não menos o homem, mas mais a natureza..." 


\title{
LEVANTAMENTO DA ENTOMOFAUNA DE PLANTAS MEDICINAIS, AROMÁTICAS E CONDIMENTARES E DESINFESTAÇÃO PELO PROCESSO DE IRRADIAÇÃO.
}

\author{
FABRICIO CALDEIRA REIS
}

\begin{abstract}
RESUMO
O presente trabalho teve como objetivo realizar o levantamento da entomofauna associada a plantas medicinais, aromáticas e condimentares desidratadas no comércio atacadista na cidade de São Paulo, empregar diferentes doses de radiação gama visando a desinfestação dos materiais e determina a dose letal de radiação gama de indivíduos adultos de Sphaericus gibboides. Foram coletados em 10 estabelecimentos no período de abril a maio de 2011 os materiais: Melissa officinalis L. (erva-cidreira), Mentha piperita L. (hortelã), Ocimum basilicum L. (manjericão), Origanum vulgare L. (orégano), Rosmarinus officinalis L. (alecrim), Thymus vulgaris L. (tomilho), Senna alexandrina Mill (sene), Coriandrum sativum L. (coentro), Petroselinum crispum (Mill.) Fuss(salsa) e Pimpinella anisum L. (erva-doce), Baccharis trimera (Less.) DC. (carqueja), Matricaria chamomilla L. (= M. recutita L.) (camomila), Laurus nobilis L. (louro) (Lauraceae); Capsicum annuum L. (páprica-doce), Bixa orellana L. (colorífico) (Bixaceae); e Peumus boldus Molina (boldo). Na primeira triagem constatou-se que todos os materiais analisados não apresentaram presença de insetos adultos. Após o período de 45 dias foram encontrados 1838 insetos adultos, oriundos de ovos e larvas. Dos substratos analisados Matricaria recutita apresentou o maior índice de infestação, com 70,6 \%. Pelmus boldus, Laurus nobilis, Matricaria recutita e Capsicum annuum, tiveram a maior diversidade de espécies. Baccharis strimera, Bixa orellana, Melissa officinalis, Origanum vulgares e Coriandrum sativum não apresentaram infestação. A espécie Lasioderma serricorne foi o inseto com maior número de indivíduos encontrados (936), maior porcentagem de infestação nos diferentes materiais $(62,5 \%)$ e maior ocorrência $(68,75 \%)$ nos materiais (M. piperita, $S$. alexandrina, $P$. anisum, $M$. chamomilla, $P$. crispum, $L$. nobilis, $C$. sativum, $C$. annuum, $O$. basilicum, $P$. boldus e $T$. vulgaris). Os seguintes materiais foram
\end{abstract}


selecionados para os ensaios de desinfestação pelo processo de irradiação: Bixa orellana, Capsicum annuum, Cassia angustifolia, Coriandrum sativum, Mentha piperita, Petrosolium sativum, Matricaria recutita. Os materiais foram infestados com adultos de L. serricorne e Sphaericus gibboides, divididos em 5 parcelas de $30 \mathrm{~g}$ com 20 indivíduos cada. Utilizando o Irradiador Multiprpósito cobalto-60 com taxa de dose no período dos ensaios de $6 \mathrm{kGy} / \mathrm{h}$, as parcelas foram submetidas a doses crescentes de radiação gama de 0 (grupo controle); 0,$25 ; 0,50 ; 0,75 ; 1,00 ; 1,25 ; 1,50 ; 1,75$ e 2,00 kGy. A determinação da dose letal para adultos de Sphaericus gibboides, procedeu-se irradiando 4 repetições por tratamento contendo 25 indivíduos cada. As doses utilizadas foram: 2,4; 2,$2 ; 2,0 ; 1,8 ; 1,6 ; 1,4 ; 1,2 ; 1,0 ; 0,8 ; 0,6$ kGy. A menor dose para a não emergência de adultos de $L$. serricorne e $S$. gibboides em todos os materiais analisados foi a de 0,25 kGy. Não foi observada a presença de adultos nas demais doses crescentes. Foi observado que os materiais adquiridos no comércio apresentaram diferentes porcentagens de infestação justificando assim a aplicação de métodos de controle. A utilização do Irradiador Multipropósito Cobalto- $60 \mathrm{com}$ taxa de dose de $6 \mathrm{kGy} / \mathrm{h}$ foi eficiente no controle de $L$. serricorne e $S$. gibboides na dose de 0,25 kGy. A dose de 2,2 kGy atingiu $100 \%$ letalidade em indivíduos adultos de S. gibboides. 


\title{
SURVEY OF INSECT FAUNA FROM PLANTS MEDICINAL, AROMATIC AND SEASONING AND DISINFESTATION THE PROCESS OF RADIATION.
}

\author{
FABRICIO CALDEIRA REIS
}

\begin{abstract}
The present study aimed to survey the insect fauna associated with medicinal plants, aromatic dehydrated and seasoning trade in São Paulo city, using different doses of gamma radiation with the aim of disinfestation of the material and determine the lethal dose of gamma radiation on Sphaericus gibboides. From April to May 2011 were collected in 10 establishments the following sample materials: Melissa officinalis L. (Lemongrass), Mentha piperita L. (Mint), Ocimum basilicum L. (Basil), Origanum vulgare L. (Oregano), Rosmarinus officinalis L. (Rosemary), Thymus vulgaris L. (Thyme), Senna alexandrina Mill (senna), Coriandrum sativum L. (Coriander), Petroselinum crispum (Mill.) Fuss (salsa) and Pimpinella anisum L. (Fennel), Baccharis trimera (Less.) DC. (Gorse), Chamomilla recutita L. (= M. recutita L.) (chamomile), Laurus nobilis L. (Blonde) (Lauraceae); Capsicum annuum L. (Sweet paprika), Bixa orellana L. (Spice) (Bixaceae) and Peumus boldus Molina (Boldo). The first screening showed that all the tested materials did not show the presence of adult insects. After 45 days 940 adult insects were found and larvae from eggs. The substrates analyzed Chamomilla recutita showed the highest rate of infestation, with 70,6\%. Pelmus boldus, Laurus nobilis, Chamomilla recutita and Capsicum annuum, had the highest species diversity. Baccharis trimera, Bixa orellana, Melissa officinalis, Origanum vulgare and Coriandrum sativum showed no infestation. The species was Lasioderma serricorne the insect with the largest number of individuals found (936), higher percentage of infestation in different materials $(62.5 \%)$ and lots, and highest occurrence $(68,75 \%)$ materials $(M$. piperita, S. alexandrian, P. anisum, Chamomilla recutita, P. crispum, L. nobilis, C. sativum, $C$. annuum, $O$. basilicum, $P$. boldus and $T$. vulgaris). The following materials were selected for testing disinfestation by irradiation process: Bixa orellana, Capsicum annuum, Cassia angustifolia, Coriandrum sativum, Mentha piperita, Petrosolium sativum, Chamomilla recutita. The materials were infested
\end{abstract}


with adults of $L$. serricorne and $S$. gibboides, divided into 5 portions of $30 \mathrm{~g}$ with 20 individuals each. Using Radiator Multiprpósito Cobalt-60 dose rate during the tests of $6 \mathrm{kGy} / \mathrm{h}$, the plots were subjected to increasing doses of gamma radiation of 0 (control), 0,$25 ; 0,50 ; 0,75 ; 1,00 ; 1,25 ; 1,50 ; 1,75$ and 2,00 kGy. The determination of the lethal dose for adults $S$. gibboides, proceeded radiating 4 replicates per treatment each containing 25 individuals. The doses used were: 3,0; 2,8; 2,6; 2,4; 2,2; 2,0; 1,8; 1,6; 1,4; 1,2; 1,0; 0,8; 0,6 kGy. The lowest dose at no emergence of adult $L$. serricorne and $S$. gibboides in all materials tested was to $0,25 \mathrm{kGy}$. We did not observe the presence of other adults in increasing doses. It was observed that the materials acquired in trade showed different percentages of infestation thus justifying the application of control methods. Using Radiator Multiprpósito Cobalt-60 with dose rate of 6 kGy was effective in controlling $L$. serricorne and $S$. gibboides at a dose of 0,25 kGy. The dose of 2,2 kGy reached $100 \%$ mortality for adults of $S$. gibboides. 


\section{SUMÁRIO}

Página

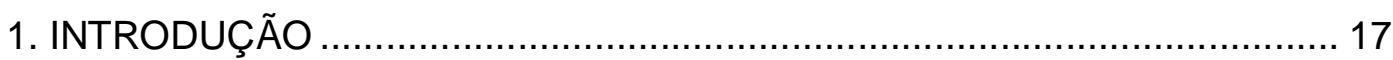

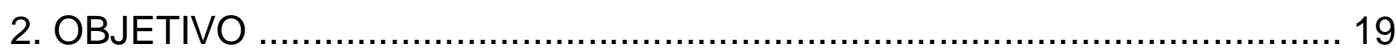

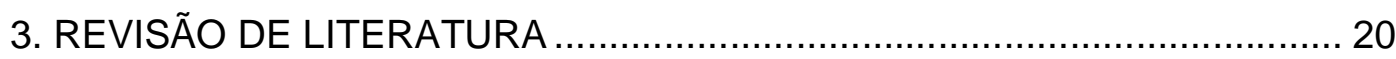

3.1 Comercialização de plantas medicinais aromáticas e condimentares.. 20

3.2 Métodos físicos no controle de insetos que infestam produtos

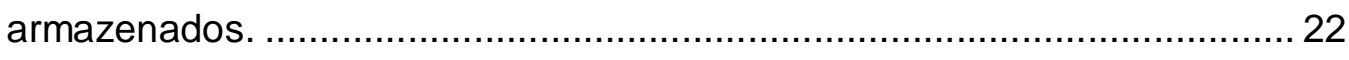

3.3 Aspectos legislativos da irradiação de alimentos ................................. 25

3.4 Fontes utilizadas na irradiação de alimentos ……………………...... 27

3.5 Características bioecológicas de insetos que infestam produtos

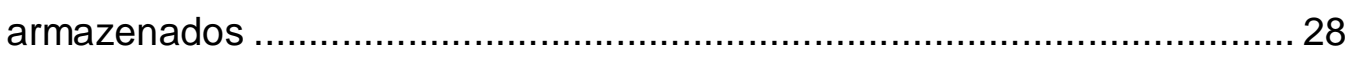

3.5.1 Lasioderma serricorne Fabricius, 1792 (COLEOPTERA: ANOBIIDAE) 30

3.4.2 Sphaericus gibboides Boieldieu, 1854 (COLEOPTERA: PTINIDAE) 33

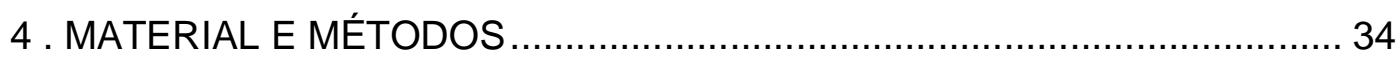

4.1 Coleta das amostras de plantas medicinais, aromáticas e condimentares

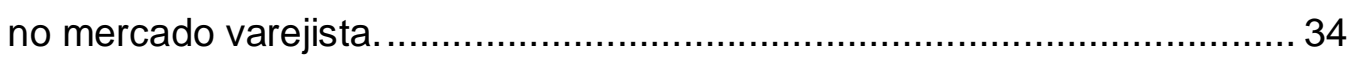

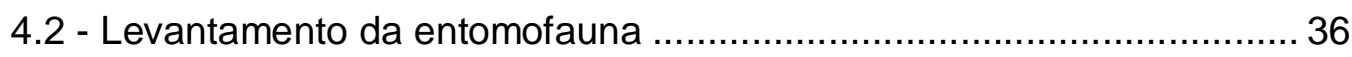

4.3 - Identificação dos insetos coletados nos diferentes materiais................ 38

4.4 - Delineamento gráfico da reprodução dos insetos utilizados no

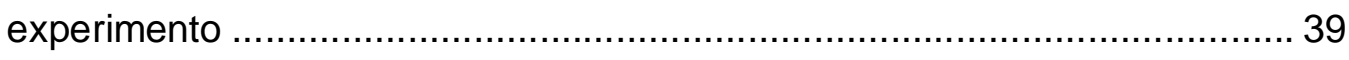

4.5 - Ensaio de irradiação dos substratos ................................................. 40

4.6 Determinação da dose letal de Sphaericus gibboides............................. 42

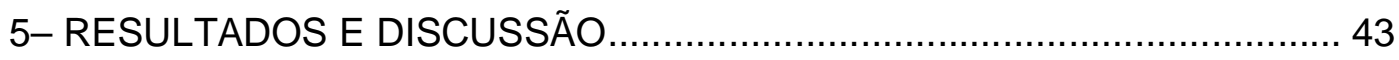

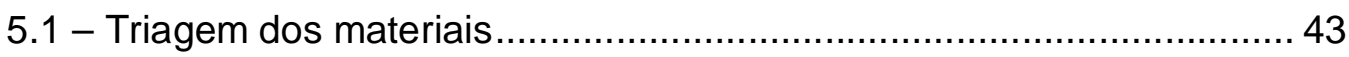

5.2 - Taxa de desenvolvimento de Lasioderma serricorne e Sphaericus gibboides. 
5.3 - Irradiação dos materiais infestados com Lasioderma serricorne ......... 53

5.4 - Irradiação dos materiais infestados com Sphaericus gibboides...........56

5.5 Determinação imediata da dose letal para Sphaericus gibboides...........59

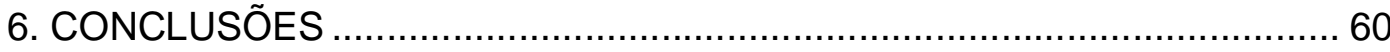

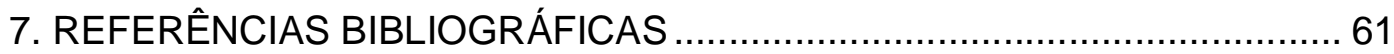




\section{LISTA DE TABELAS}

Página

Tabela 1. Quantificação de insetos por substrato (\% total de infestação dos substratos nos diferentes lotes analisados) 44

Tabela 2. Número total de insetos (45 dias) e \% de infestação nos diferentes materiais provenientes de estabelecimentos atacadistas na cidade de São Paulo/SP

Tabela 3. Número de Oryzaephilus sp encontrados nos diferentes substratos, coletados no período de abril a novembro de 2011. 46

Tabela 4. Número de Cryptolestes sp encontrados nos diferentes substratos, coletados no período de abril a novembro de 2011. 46

Tabela 5. Número de Ephestia sp encontradas nos diferentes substratos, coletadas no período de abril a novembro de 2011.

Tabela 6. Número de Sphaericus gibboides encontrados nos diferentes substratos, coletadas no período de abril a novembro de 2011. 47

Tabela 7. Número de Lasioderma serricorne encontradas nos diferentes substratos, coletadas no período de abril a novembro de 2011

Tabela 8. Número total e Média* de adultos emergidos de Lasioderma serricorne nos diferentes substratos. Março de 2012.

Tabela 9. Número total e Média* de adultos emergidos de Sphaericus gibboides nos diferentes substratos desidratado. Março de 2012 50 
Tabela 10. Número total e média de adultos (Lasioderma serricorne) emergidos no substrato Bixa orellana (Colorífico) irradiados com doses crescentes de radiação gama. Agosto a Outubro de 2012 ............................... 53

Tabela 11. Número total e média de adultos (Lasioderma serricorne) emergidos no substrato Capsicum annuum (Páprica doce) irradiados com doses crescentes de radiação gama. Agosto a Outubro de 2012 53

Tabela 12. Número total e média de adultos emergidos (Lasioderma serricorne) no substrato Cassia angustifolia (Sene) irradiados com doses crescentes de radiação gama. Agosto a Outubro de 2012 ............................... 54

Tabela 13. Número total e média de adultos (Lasioderma serricorne) emergidos no substrato Coriandrum sativum (Coentro) irradiados com doses crescentes de radiação gama. Agosto a Outubro de 2012 .............................. 54

Tabela 14. Número total e média de adultos (Lasioderma serricorne) emergidos no substrato Mentha piperita (Hortelã) irradiados com doses crescentes de radiação gama. Agosto a Outubro de 2012............................... 54

Tabela 15. Número total e média de adultos de (Lasioderma serricorne) emergidos no substrato Petrosolium sativum (Salsa) irradiados com doses crescentes de radiação gama. Agosto a Outubro de 2012 ............................... 55

Tabela 16. Número total e média de adultos (Sphaericus gibboides) emergidos no substrato Capsicum annuum (Páprica doce) irradiados com doses crescentes de radiação gama. Agosto a Outubro de 2012 .............................. 56

Tabela 17 Tabela 12 - Número total e média de adultos (Sphaericus gibboides) emergidos no substrato Mentha piperita (Hortelã) irradiados com doses crescentes de radiação gama. Agosto a Outubro de 2012 ............................... 56 
Tabela 18. Número total e média de adultos (Sphaericus gibboides) emergidos no substrato Bixa orellana (Colorífico) irradiados com doses crescentes de radiação gama. Agosto a Outubro de 2012 .................................................. 57

Tabela 19. Número total e média de adultos (Sphaericus gibboides) emergidos no substrato Chamomila recutita (Camomila) irradiados com doses crescentes de radiação gama. Agosto a Outubro de 2012 ............................................. 57

Tabela 20. Número total e média de adultos (Sphaericus gibboides) emergidos no substrato Pimpinella anisum (Erva doce) irradiados com doses crescentes de radiação gama. Agosto a Outubro de 2012 ............................................... 57

Tabela 21. Número total e média de adultos (Sphaericus gibboides) emergidos no substrato Petrosolium sativum (Salsa) irradiados com doses crescentes de radiação gama. Agosto a Outubro de 2012 ................................................ 58

Tabela 22 - Avaliação da eficiência de dose crescentes de radiação gama $\left({ }^{60} \mathrm{CO}\right)$ sobre adultos de Sphaericus gibboides. Mortalidade por dose (Média*) e porcentagem de eficiência $\left(\% \mathrm{E}^{\star \star *}\right)$. São Paulo, Março de 2013........................ 59 


\section{LISTA DE FIGURAS}

Página

Figura 1. Radura: símbolo utilizado em produtos irradiados ........................... 26

Figura 2. Adulto de Lasioderma serricorne .................................................... 30

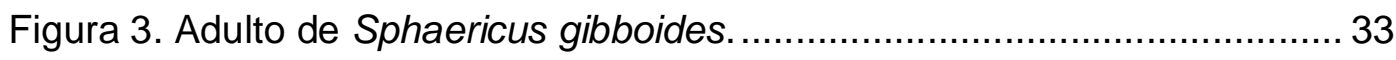

Figura 4. Acondicionamento dos materiais coletados ................................... 36

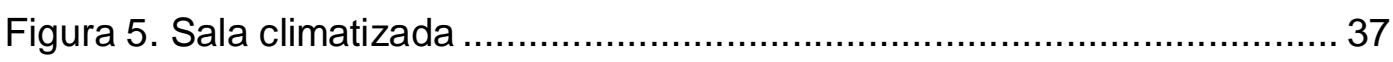

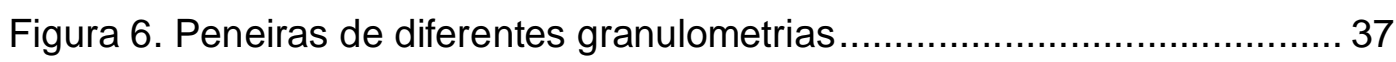

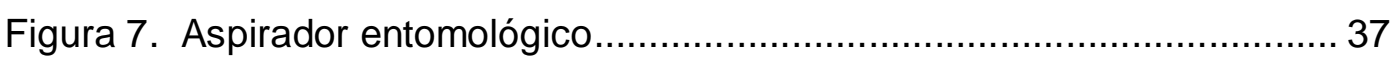

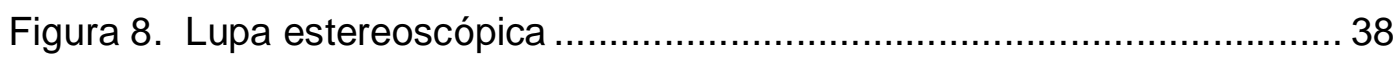

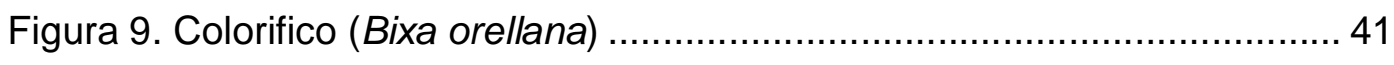

Figura 10. Salsa (Petroselium sativum) ……................................................. 41

Figura 11. Erva doce (Pinpenella anisum) .................................................. 41

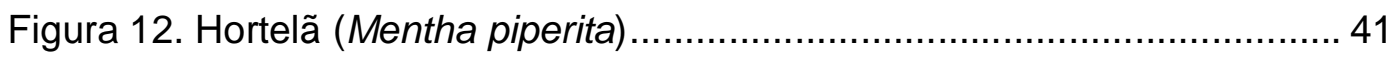

Figura 13. Camomila (Chamomila recutita) ................................................. 41

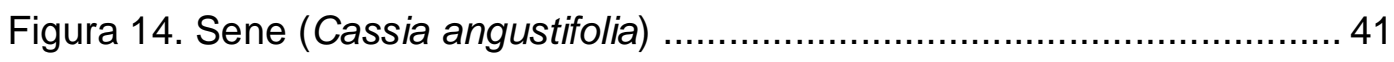

Figura 15. Coentro (Coriandrum sativum) ………......................................... 41

Figura 16. Páprica doce (Capsisum annuum) ………..................................... 41

Figura 17. Porcentagem de infestação por espécie nos lotes analisados ........ 45

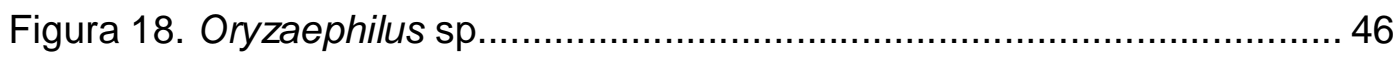

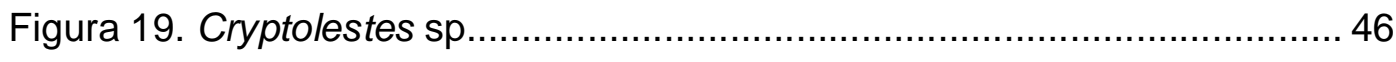

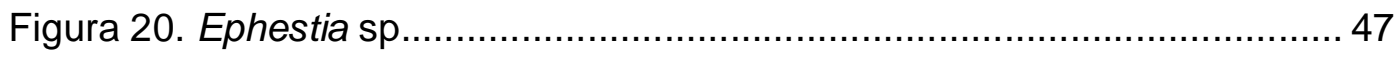

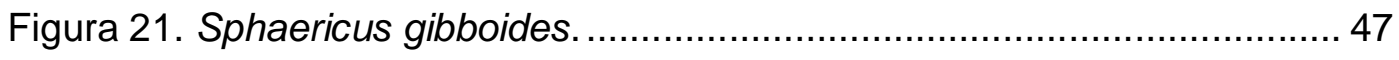

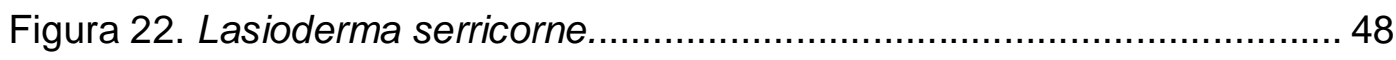

Figura 23. Média de adulto emergidos de Lasioderma serricorne no diferentes

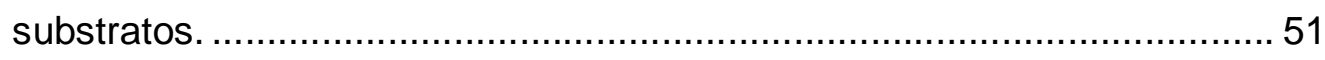


Figura 24. Média de adulto emergidos de Sphaericus gibboides no diferentes substratos. 51

\section{LISTA DE QUADROS}

Página

Quadro 1. Efeito da temperatura sobre insetos que infestam produtos armazenados. 22

Quadro 2. Tipos de fontes de radiação e suas características. 28

Quadro 3. Plantas medicinais aromáticas e condimentares coletadas no mercado varejista da cidade de São Paulo/SP 35

Quadro 4. Materiais infestados utilizados no bioensaio de irradiação dos materiais 40 


\section{INTRODUÇÃO}

Ao longo da evolução da espécie humana, houve grande acúmulo de conhecimentos sobre o uso das plantas utilizadas na alimentação e na saúde, incluindo medicinais, aromáticas e condimentares. Fatores de ordem econômica levaram ao direcionamento das atenções às grandes culturas, delegando às plantas medicinais, aromáticas e condimentares a ocupação de um espaço secundário, nas propriedades, nas pesquisas, na literatura e noutras atividades (SANTOS 1993).

O Brasil tem a maior biodiversidade de plantas do planeta associada à rica diversidade étnica e cultural, com um maior percentual de plantas medicinais encontradas na Amazônia, no Cerrado e na Mata Atlântica, respectivamente (AZEVEDO, 2003).

De acordo com BOTSARIS (1995), para melhorar a qualidade das especiarias, plantas medicinais entre outros alimentos comercializados, há necessidade de métodos adequados de manipulação, iniciando-se na identificação correta da espécie, coleta adequada, pré-tratamento e armazenamento corretos e termina com a preparação e utilização terapêutica, que também devem ser adequados para que os resultados sejam satisfatórios.

MORGAN (1994), afirma que a falta de controle no armazenamento das plantas, causam a sua deterioração, pois em contato com o ar, a luz, a umidade e a poeira causam a inibição dos elementos orgânicos. FIORENZE, 2002, citado por ALDRIGUE, 2002, mostra também a importância do correto armazenamento, transporte, comercialização que são fatores limitantes aos produtos alimentícios.

SANTOS (1993) demonstrou que o armazenamento prolongado só pode ser realizado quando se adotam corretamente as práticas de colheita, limpeza, secagem e controle de insetos e fungos. Entretanto, as ervas e especiarias, (devido aos métodos e princípios de controle inadequados em muitos casos) 
acabam oferecendo para o comércio um alimento impróprio para consumo (VIZEU, 2004).

Segundo VIZEU (2004) a eliminação da contaminação ou infestação requer que o produto seja submetido a algum tipo de tratamento. As alternativas para a descontaminação são o vapor e o calor que, em via de regra, alteram o conteúdo do princípio ativo. Para a desinfestação, temos ainda a fumigação que pode deixar resíduos tóxicos no produto e como última alternativa viável o uso da radiação ionizante, que segundo HOUSSAIN et al., (1972), ARTHUR et al., (1973) e WIENDL et al., (1973 e 1974), a irradiação não induz o aparecimento da resistência nos insetos, e nem resíduos nos alimentos.

A grande vantagem do processo com radiação ionizante está em podermos dimensionar a dose de radiação mínima para obter o efeito desejado, minorando assim alterações que o produto possa sofrer entre outras vantagens (VIZEU, 2004). 


\section{OBJETIVO}

- Levantamento da entomofauna associada a plantas medicinais, aromáticas e condimentares desidratadas comercializados na cidade de São Paulo.

- Emprego da radiação gama do Cobalto-60 como tratamento quarentenário de plantas medicinais, aromáticas e condimentares desidratadas infestadas por Lasioderma serricorne e Sphaericus gibboides

- Determinação da dose letal imediata para indivíduos adultos de Sphaericus gibboides através da radiação gama do Cobalto-60. 


\section{REVISÃO DE LITERATURA}

\subsection{Comercialização de plantas medicinais aromáticas e condimentares}

As plantas medicinais, condimentares e aromáticas tiveram, recentemente, um aumento no seu cultivo e comercialização, tanto pelas inúmeras pesquisas que demonstram seus efeitos fitoterápicos, como pelo emprego de algumas delas na culinária, proporcionando aroma e sabor agradáveis aos alimentos (RUSSOMANO, 2010).

A Associação Brasileira da Indústria Fitoterápica (ABIFITO), estimou que os gastos em terapias naturais chegaram a 47 bilhões de dólares no ano 2007.

Para a América Latina, junto com a África, faz-se uma estimativa de gastos de 3 bilhões de dólares. (HERBARIUM, 2002).

Os dados do Departamento de Operações de Comércio Exterior (DECEX) referentes ao comércio internacional do Brasil confirmam o crescimento do mercado. No período de 1990 a 2000, o crescimento da exportação de Plantas Medicinais foi de $159 \%$ e de especiarias foi de $65 \%$. Nas importações, o crescimento foi de $148 \%$ para Plantas Medicinais e de $97 \%$ para especiarias.

Conforme FERREIRA (1998), planta medicinal pode ser definida como plantas que possuem atividade biológica, com um ou mais princípios ativos úteis à saúde. A utilização de medicamentos, suplementos e chás a base destas plantas é caracterizada como fitoterapia.

Segundo FUZÉR \& SOUZA (2003), a utilização de plantas medicinais para produção de medicamentos apresenta uma melhor relação custo/benefício quando comparada aos produtos sintéticos, pois sua ação biológica é eficaz com baixa toxidade e efeitos colaterais, além de apresentar um custo de produção inferior e, consequentemente, um preço de venda menor. Entretanto, estes medicamentos não são necessariamente mais barato 
que os sintéticos, pois necessita de matéria-prima de qualidade, para que a planta possa apresentar as substâncias ativas, além de grandes quantidades de planta, o que acaba encarecendo o processo. Além disso, o medicamento sintético normalmente tem uma especificidade muito alta, o que permite que se usem doses baixas, 5 a 10mg, enquanto que com os extratos vegetais, é necessário usar doses de 300 a 500mg para obtenção do efeito (ABIFISA, 2007).

O consumo de medicamentos fitoterápicos tem aumentado consideravelmente nas últimas duas décadas, tanto nos países desenvolvidos, como naqueles em desenvolvimento. Somente na Europa, o mercado dos medicamentos fitoterápicos atinge cerca de 7 bilhões de dólares ao ano, sendo a Alemanha responsável por 50\% deste valor (FITOTERAPIA, 2007).

O Brasil, mesmo perante a importância desse mercado, não existem dados oficiais de quanto movimenta a indústria de fitoterápicos. Estima-se algo em torno de 1 bilhão de reais/ano (ABIFISA, 2007).

As plantas aromáticas e as especiarias são ricas em óleos essenciais caracterizados por uma notável atividade antimicrobiana, e por esta razão, seus produtos derivados podem ser usados para retardar ou inibir o crescimento de microrganismos patogênicos e/ou deteriorantes (MARINO et al., 2001).

Embora possam ou não contribuir com o valor nutricional de uma dieta, as especiarias podem ser fontes de antioxidante natural relevante, desde que sejam utilizadas tradicionalmente como ingredientes, o que permite que sejam facilmente e diretamente empregadas por suas propriedades antioxidantes em alimentos e possivelmente em outros sistemas (LEE et al., 2003). 


\subsection{Métodos físicos no controle de insetos que infestam produtos armazenados.}

Os métodos físicos eram a principal forma de proteção dos grãos antes do extensivo uso de químicos sintéticos.

A utilização de altas ou baixas temperaturas pode ser empregada para 0 controle de insetos. A temperatura interfere diretamente nas fases do ciclo biológico de cada inseto, sendo assim, esta pode ser utilizada para retardar a multiplicação ou eliminar a população. (Quadro 1).

Quadro 1. Efeito da temperatura sobre insetos que infestam produtos armazenados.

\begin{tabular}{|c|c|c|}
\hline Ação & $\begin{array}{c}\text { Faixa de } \\
\text { temperatura } \\
\left({ }^{\circ} \mathrm{C}\right)\end{array}$ & Efeito esperado \\
\hline \multirow[t]{4}{*}{ Letal } & $\geq 62$ & Morte em menos de 1 minuto \\
\hline & 50 a 60 & Morte em menos de 1 hora \\
\hline & 45 a 50 & Morte em menos de 1 dia \\
\hline & 35 a 42 & Populações podem morrer \\
\hline Sub-ótimo & 35 & Temperatura máxima para reprodução \\
\hline & 32 a 35 & Lento crescimento populacional \\
\hline Ótimo & 25 a 32 & $\begin{array}{c}\text { Máxima taxa de crescimento } \\
\text { populacional }\end{array}$ \\
\hline Sub-ótimo & 13 a 25 & Lento crescimento populacional \\
\hline \multirow[t]{4}{*}{ Letal } & 5 a 13 & Lenta mortalidade populacional \\
\hline & 3 a 5 & Cessam os movimentos \\
\hline & $-10 a-5$ & Morte em alguns dias \\
\hline & $-25 a-15$ & Morte em menos de 1 hora \\
\hline
\end{tabular}


Temperaturas abaixo de um determinado limite podem causar a inativação de enzimas ou de nutrientes com maior rapidez com que são sintetizadas, afetando os processos metabólicos dos insetos (LANGRIDGE, 1966).

A exposição do inseto em determinadas fases da vida, a baixas temperaturas, pode fazer com que os danos acumulados se manifestem na fase seguinte do ciclo biológico (HOWE, 1966).

A morte do inseto, nestas condições, pode ser causada por acumulo de produtos tóxicos, ausência de absorção de nutrientes, desidratação e injúria mecânica por cristais de gelo nos fluídos corporais. (MULLEN \& ARBOGAST, 1983).

O Japão, um dos mercados mais exigentes do mundo, permite a importação de frutas de países onde ocorrem Anastrepha suspensa mediante tratamento com frio à $1,7^{\circ} \mathrm{C}$ por 19 dias (BENSCHORTER, 1984).

A tolerância ao frio por Carpophilus hemipterus e Carpophilus mutilatus, pragas de grãos armazenados foi avaliada em laboratório por DONAHAYE et al. 1991, apresentando variação entre as espécies e formas de vida. A 5ํ C a população pereceu em 89 horas, enquanto as formas mais latentes morreram no máximo em 317 horas a $0^{\circ} \mathrm{C}$.

A exigência do USDA (Departamento de Agricultura dos Estados Unidos) quanto aos tratamentos térmicos de frutas destinadas aos EUA, requer o controle total de insetos a níveis próximos a 100\% (MOSS \& CHAN, 1993).

Resultados indicam possibilidade do uso eficiente desse método, no entanto em alguns casos o controle total não foi obtido (HALLMAN, 1990).

Combinações tempo-temperatura são necessárias para inativar certas espécies de insetos não são tolerados pelos frutos, que perdem qualidade 
(firmeza de polpa, brilho da casca e, provavelmente, atividade enzimática) podendo diminuir o período de comercialização após o tratamento.

A redução da temperatura da massa de grãos para menos de $13^{\circ} \mathrm{C}$, em geral ira determinar a eliminação da população, uma vez que a taxa de multiplicação não será suficiente para mantê-la. Esta baixa temperatura pode ser atingida com ar introdução de ar frio no ambiente, através de equipamentos de aeração refrigerada. (BANKS \& FIELDS, 1995).

Temperaturas acima de $42^{\circ} \mathrm{C}$ levam a maioria das populações à morte. A alta temperatura pode ser atingida com a introdução de ar aquecido ou utilizando aparelhos que emitem micro-ondas, levando sempre em consideração que tanto a temperatura de exposição do material quanto o tempo de duração do calor podem afetar a qualidade final do produto uma vez que os limiares são muito próximos (BANKS \& FIELDS, 1995). 


\subsection{Aspectos legislativos da irradiação de alimentos}

A irradiação de alimentos possui a capacidade de destruir patogênicos e deteriorantes presentes nos alimentos. É empregada, ainda, para eliminar insetos e retardar o processo germinativo em produtos vegetais. Desta forma, há um aumento na segurança dos alimentos destinados ao consumo humano e uma redução nas perdas (RESURRECCION, 1955).

A legislação brasileira segue as recomendações internacionais sugeridas pela Food and Agriculture Organization (FAO), International Atomic Energy Agengy (IAEA) e Codex Alimentarium, da Organização das Nações Unidas (ONU).

No Brasil, existe regulamentação sobre a irradiação de alimentos desde 1973 e portarias complementares foram editadas em 1985 e 1989 (OLIVEIRA, 2000).

A Portaria no 30 de 02/08/89, da Divisão de Alimentos do Ministério da Saúde, determinava o limite superior de irradiação de 10 kGy, a lista de produtos aprovados para irradiação e suas respectivas doses proibia a reirradiação. Em 26/01/2001, a Diretoria Colegiada da Agência Internacional de Vigilância Sanitária, (ANVISA), aprovou a Resolução (RDC) № 21, que não restringe quais alimentos podem ser irradiados e nem a dose máxima absorvida para se obter o fim desejado, desde que não haja prejuízo nas suas qualidades funcionais e sensoriais (EMBRARAD, 2012).

Segundo a RDC № 21, qualquer alimento pode ser irradiado desde que sejam observadas as seguintes condições:

- a dose mínima absorvida deve ser suficiente para alcançar a finalidade pretendida;

- a dose mínima absorvida deve ser inferior àquela que comprometa as propriedades funcionais e/ou atributos sensoriais dos alimentos; 
- a embalagem deve ter condições higiênicas aceitáveis para o processo de irradiação.

A RDC n 21 estabelece ainda que, quando um produto irradiado é usado como ingrediente em outro alimento, este fato deve ser mencionado na embalagem final com o símbolo da "radura" indicando que o alimento foi tratado por irradiação (FIGURA 1). No caso das especiarias este é um aspecto importante, desde que elas sejam utilizadas na fabricação de outros produtos,como os derivados de carne (LEAL et al., 2004).

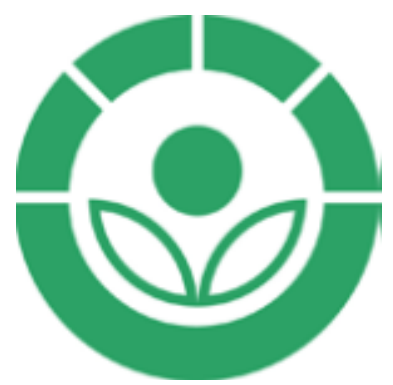

Figura 1. Radura: símbolo utilizado em produtos irradiados 


\subsection{Fontes utilizadas na irradiação de alimentos}

De acordo com o Codex General Standard for Irradiated Foods do Codex Alimentarius (1984), para irradiação de alimentos só são permitidos os raios gama, provenientes dos radionuclídeos ${ }^{60} \mathrm{Co}$ e ${ }^{137} \mathrm{Cs}$; máquinas de raios $\mathrm{X}$ possuindo uma energia máxima de cinco milhões de eletronvolt ( $\mathrm{MeV}$ ); ou aceleradores de elétrons com um máximo de $10 \mathrm{MeV}$. O radionuclídeo mais utilizado na irradiação de alimentos por raios gama é o ${ }^{60} \mathrm{Co}$, produzido pelo bombardeamento com nêutrons, em um reator nuclear, do metal ${ }^{59} \mathrm{Co}$. Este então, duplamente encapsulado em "lápis" de aço inoxidável para impedir qualquer fuga durante seu uso em um irradiador (CODEX ALIMENTARIUS, 1984).

As radiações utilizadas nesse processo são: raios gama de alta energia, raios $X$ e feixes de elétrons (Quadro 2). Estas radiações também são classificadas como radiações ionizantes, pois sua energia é alta o suficiente para converter átomos e moléculas em íons pela remoção de elétrons (FAO/IAEA, 1999).

Os raios gama são extremamente penetrantes, enquanto os raios $X$ são menos penetrantes e possui um baixo rendimento em sua produção, somente de 3 a $5 \%$ da energia aplicada é efetivamente convertida em raios $X$. Os elétrons possuem pouca penetrabilidade nos alimentos em relação aos raios gama e os raios $X$ (CENA, 2012). 
Quadro 2. Tipos de fontes de radiação e suas características.

\begin{tabular}{|cl|}
\hline Fonte de radiação & \multicolumn{1}{c|}{ Características } \\
\hline Cobalto-60 & 1. Elevado poder penetrante \\
& $\begin{array}{l}\text { 2. Fonte radioativa permanente } \\
\text { 3. Alta eficiência }\end{array}$ \\
\hline Feixes de elétrons & 1. Baixo poder penetrante \\
& 2. Fonte não permanente \\
& 3. Necessário resfriar o aparelho \\
& 1. Elevado poder penetrante \\
Raios-X & 2. Baixa eficiência \\
& 3. Tecnicamente complexo
\end{tabular}

Fonte: DIANA 2010

\subsection{Características bioecológicas de insetos que infestam produtos armazenados}

Segundo PERIOTO (2005) praga é qualquer espécie, biótipo ou raça de animal, vegetal ou outro agente patogênico nocivo aos vegetais e seus subprodutos, enquanto, as pragas quarentenárias são aquelas com importância econômica para o local, onde ainda não está presente ou caso esteja, não se encontra largamente distribuída e é oficialmente controlada.

A condição de praga de uma população de insetos depende da abundância de indivíduos, assim como o tipo de perda ou danos causados pelos insetos em produtos armazenados (GULLAN \& CRANSTON, 1994).

Os insetos predadores de grãos e seus subprodutos são os maiores causadores de perdas físicas em armazéns, além de serem responsáveis pela 
perda na qualidade e quantidade no momento que são destinados a comercialização (LORINI, 2002).

Normalmente os insetos que atacam e danificam os produtos armazenados pertencem à ordem Coleoptera (carunchos, besouros e gorgulhos) e a ordem Lepidoptera (mariposas e traças) compreendendo as espécies de maior importância como pragas, pois são causadoras de danos significativos aos produtos (CROWSON, 1981).

Segundo GALLO et al. (2002) os coleópteros adultos (carunchos, besouros e gorgulhos) são insetos de tamanho pequeno e possuem o primeiro par de asas (élitros) muitos resistentes, devido a essa característica, conseguem se movimentar em espaços reduzidos da massa armazenada. Já os lepidópteros adultos (mariposas e traças) são insetos maiores e possuem dois pares de asas membranosas bem menos resistentes que os élitros, por isso não conseguem movimentar-se bem na massa armazenada, ficando sua ação restrita às superfícies. 


\subsubsection{Lasioderma serricorne Fabricius, 1792 (COLEOPTERA: ANOBIIDAE)}

A espécie Lasioderma serricorne (Fabricius, 1792) (Coleoptera: Anobiidae), considerada cosmopolita, causa considerável dano a uma grande variedade de produtos armazenados, incluindo oleaginosas, cereais, farinhas, folhas de fumo e frutas secas. Em tais produtos tanto as larvas quanto os adultos escavam galerias, danificando-os completamente (POWELL, 1931).

O coleóptero adulto (Figura 2) é ovóide, tamanho de 2,0 - 3,0 $\mathrm{mm}$. Coloração castanho avermelhado, apresentando cerdas finas e claras no corpo. A cabeça é defletida sob o prótorax, dando uma aparência corcunda.

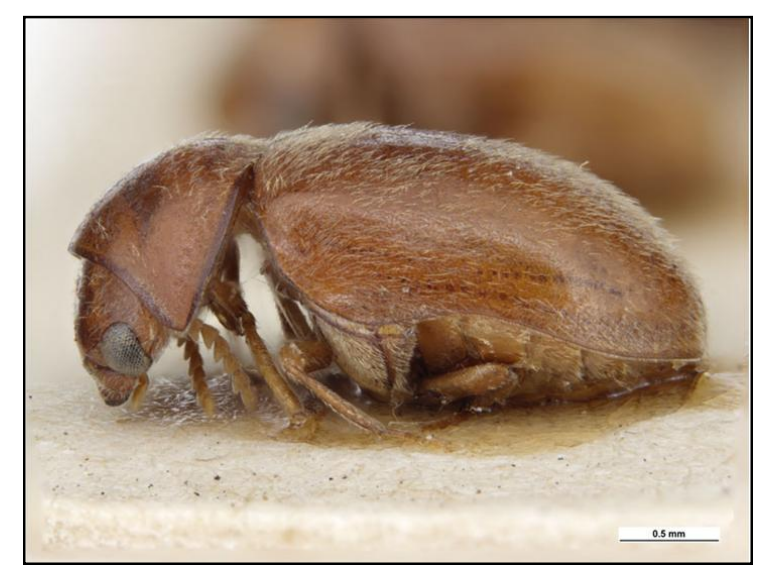

Figura 2. Adulto de Lasioderma serricorne. Fonte: Padil 2013

Élitros lisos sem estrias ou pontuações. Antenas com onze segmentos,

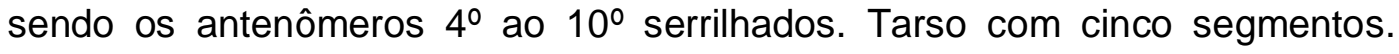
Mandíbula com aparência triangular, apresentando dois dentes triangulares apicais e não apresentam projeção molar (ASHWORT, 1993; PACHECO \& PAULA, 1995; CAMPOS \& ZORZENON, 2006).

São insetos voadores, característica que contribui para a dispersão e aumento da infestação. Apresentam maior atividade ao entardecer e a noite, podendo haver ocorrências de atividade a luz do dia, principalmente em dias com baixa irradiação solar (ASHWORT, 1993). 
As fêmeas sexualmente maduras liberam feromônio para atrair os machos e copular. Após a cópula, as fêmeas saem em busca de locais mais apropriados para desovar colocando em torno de 40 a 50 ovos. Ovipositam diretamente no substrato e marcam o local para que outras fêmeas não depositem seus ovos no mesmo lugar, diminuindo a competição de alimento das larvas e aumentando a dispersão da infestação. (PACHECO \& PAULA, 1995).

O ovo desta espécie é ligeiramente oval de coloração branco opaco, possuindo microgranulações irregulares na base. A porção anterior do ovo apresenta microestruturas protuberantes dispostas em padrões pentagonais (KUCEROVÁ \& STEJSKAL, 2010).

As larvas eclodem do ovo aproximadamente em $6-8$ dias, dependendo das condições ambientais. Ovos mantidos a $20^{\circ} \mathrm{C}$ eclodem em média após 22 dias (PACHECO \& PAULA, 1995).

Bastante ágeis, as larvas causam a maior parte dos danos nos produtos, são brancas e escarabeiformes, apresentam cabeça distinta e não retraída para o protórax. Corpo levemente curvado, coberto por pêlos finos. Os espiráculos torácicos estão distantes da parte anterior do protórax. Pernas segmentadas. Diferencia-se das larvas de outros anobiídeos por não apresentar fileiras de espinhos nos segmentos abdominais. Podem sofrer quatro a seis ínstares. O estágio larval é totalmente influenciado pelas condições ambientais. Em temperatura de $20^{\circ} \mathrm{C}$ pode durar em média mais de 60 dias enquanto em temperatura de $30^{\circ} \mathrm{C}$ pode durar em média de 28 dias (PACHECO \& PAULA, 1995).

Após este estagio larval vem o estágio de pré-pupa, que é caracterizada pela falta de alimentação da larva e a construção de um envoltório rígido feito de partículas alimentares e secreção. Nesse estágio o individuo sofre um processo complexo de metamorfose até se transformar em pupa. O sexo das pupas pode ser distinguido pelas papilas genitais, onde os machos apresentam papilas globulares não protuberantes e as fêmeas apresentam papilas 
protuberantes, trissegmentada e divergentes. O período do estágio de pupa pode variar de quatro dias ou mais (ASHWORT, 1993).

O indivíduo emerge do casulo adulto e sexualmente ativo. Vivem em média de duas a sete semanas. Os fatores ambientais interferem diretamente no ciclo de vida da espécie, sendo a temperatura e a umidade fatores chave que podem tanto acelerar quanto retardar o desenvolvimento dos indivíduos e aumentar ou diminuir a mortalidade em todos os estágios de vida. A espécie Lasioderma serricorne é pouco resistente ao frio, não sobrevivendo por muitos dias se exposto a temperaturas de $0-5^{\circ} \mathrm{C}$, sendo também sensível a temperaturas muito altas, não sobrevivendo em nenhum dos estágios de vida se exposto a $40^{\circ} \mathrm{C}$ ou acima. O valor da taxa de umidade interfere na cronologia do ciclo, pois, em umidades elevadas (quando a temperatura não é limitante) o desenvolvimento se dá de forma longa e a taxa de mortalidade aumenta, sendo que também em níveis baixos de umidades ocorre o mesmo. O ciclo de vida pode ser completo na faixa de temperatura de 20 a $37,5^{\circ} \mathrm{C}$, com a umidade relativa ideal. As condições mais favoráveis para a espécie são: umidade relativa de 70 a $80 \%$ e a temperatura em torno de $32,5^{\circ} \mathrm{C}$. (ASHWORT, 1993; PACHECO \& PAULA, 1995).

O tipo de alimento também influência o ciclo do inseto, podendo levar 68 dias para o desenvolvimento se completar em tabaco e menos de 20 dias em farinha de trigo com leveduras (EDDE et al., 2012). 


\subsubsection{Sphaericus gibboides Boieldieu, 1854 (COLEOPTERA: PTINIDAE)}

As especies que compreendem o genero Sphaericus possuem o corpo arredondado com $3 \mathrm{~mm}$ aproximadamente (Figura 3) em ambos os sexos. Esta especie possui hábitos alimentares onívoros, e são freqüentemente encontrados infestando produtos armazenados. GRACE (1988) descreveu a ocorrencia desta espécie em fava seca, sálvia brava, pinheiro-real e pinheirodo-colorado.

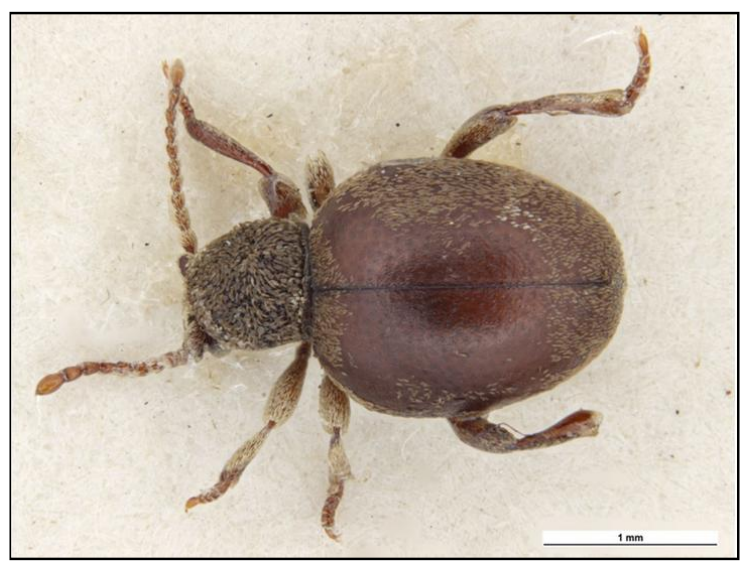

Figura 3. Adulto de Sphaericus gibboides. Fonte: Padil 2013 


\section{MATERIAL E MÉTODOS}

4.1 Coleta das amostras de plantas medicinais, aromáticas e condimentares no mercado varejista.

O levantamento foi realizado no período de abril a maio de 2011, coletando-se 16 materiais (Quadro 3) em 10 estabelecimentos varejistas localizados na região central da cidade São Paulo/SP, em amostras de 250 a $1000 \mathrm{~g}$. 
Quadro 3. Plantas medicinais aromáticas e condimentares coletadas no mercado varejista da cidade de São Paulo/SP

\begin{tabular}{|c|c|c|}
\hline Família botânica & Nome cientifico & Nome popular \\
\hline \multirow{3}{*}{ Apiaceae (Umbelliferae) } & Petroselium sativum L. & Salsa \\
\hline & Pimpinella anisum $\mathrm{L}$. & Erva Doce \\
\hline & Coriandrum sativum $\mathrm{L}$. & Coentro \\
\hline \multirow{2}{*}{ Asteraceae (Compositae) } & Chamomila recutita L. & Camomila \\
\hline & Baccharis trimera (Less) & Carqueja \\
\hline Bixaceae & Bixa orellana L. & Colorífico \\
\hline \multirow[t]{4}{*}{$\begin{array}{c}\text { Fabaceae } \\
\text { (Caesalpinioideae) }\end{array}$} & Cassia angustifolia Vahl & Sene \\
\hline & Origanum vulgare L. & Orégano \\
\hline & Ocimum basilicum $\mathrm{L}$ & Manjericão \\
\hline & Melissa officinalis L. & Erva cidreira \\
\hline \multirow[t]{4}{*}{ Lamiaceae (Labiatae) } & Mentha piperita Ehrh. & Hortelã \\
\hline & Rosmarinus officinalis L. & Alecrim \\
\hline & $\begin{array}{c}\text { Plectranthus barbatus } \\
\text { Andrews } \\
\end{array}$ & Boldo \\
\hline & Thymus vulgaris $\mathrm{L}$. & Tomilho \\
\hline Lauraceae & Laurus nobolis L. & Louro \\
\hline Solanaceae & Capsicum annuum L. & Páprica doce \\
\hline
\end{tabular}




\section{2 - Levantamento da entomofauna}

Após a coleta, procedeu-se a triagem dos materiais no Laboratório de Artrópodes do Instituto Biológico (IB/SP).

De cada amostra adquirida foi retirado uma alíquota de 50g, acondicionada em recipiente plástico (Figura 4) de dimensões de $13 \times 11 \mathrm{~cm}$ com tampa devidamente telada, permitindo seu isolamento, evitando assim infestações cruzadas. Foram realizadas triagens com 0 e 45 dias, possibilitando coletar os insetos oriundos de ovos e larva.

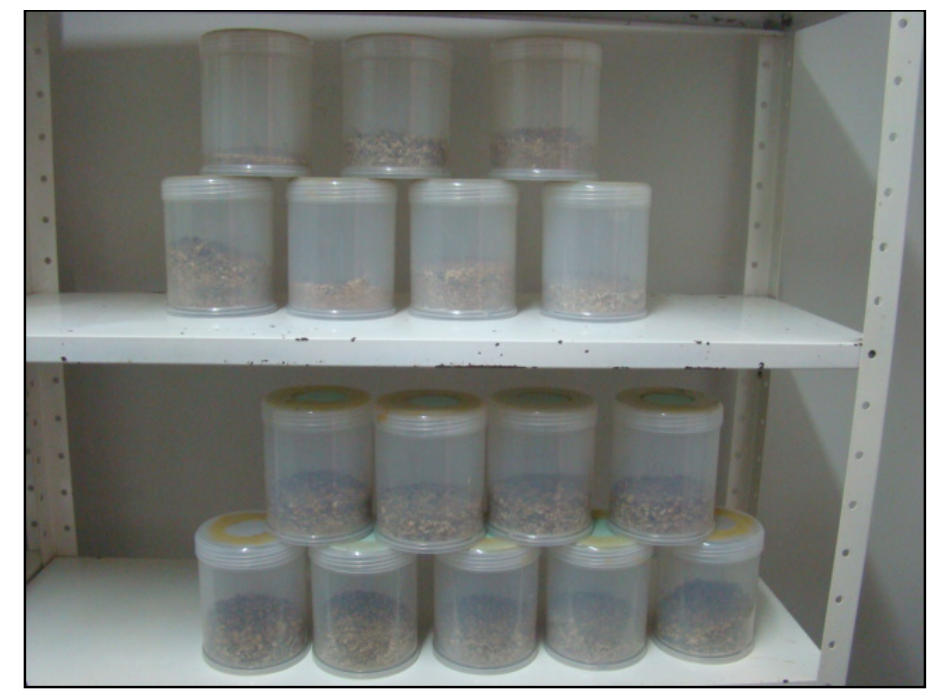

Figura 4. Acondicionamento dos materiais coletados

As amostras foram mantidas em sala climatizada (Figura 5) com $27 \pm$ $2^{\circ} \mathrm{C}$ de temperatura e umidade relativa de $70 \pm 5 \%$. Para a coleta dos insetos foi utilizado peneiras de diferentes granulometrias (Figura 6) e aspirador entomológico (Figura 5). Os insetos capturados foram acondicionados em frascos etiquetados com dimensões de $3,5 \times 1,5 \mathrm{~cm}$, contendo álcool $80 \%$, para posterior identificação. 


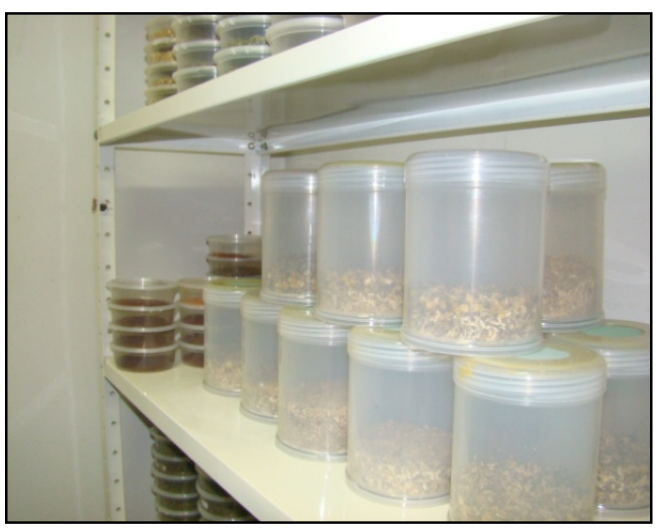

Figura 5. Sala climatizada

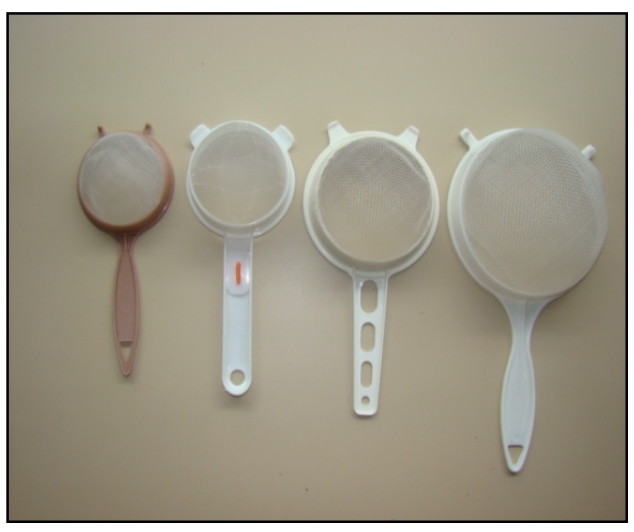

Figura 6. Peneiras de diferentes granulometrias

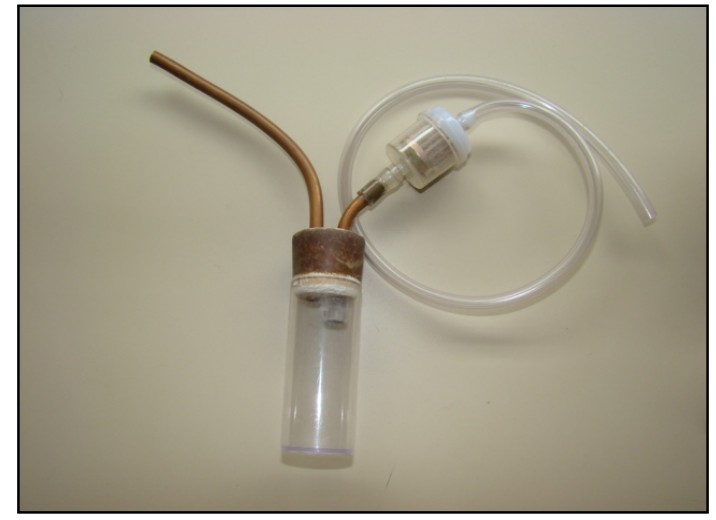

Figura 7. Aspirador entomológico 


\section{3 - Identificação dos insetos coletados nos diferentes materiais}

Os insetos foram identificados com o auxílio de lupa estereoscópica (em aumento de 10X) (Figura 8) de acordo com os seguintes autores REES (2007); PEREIRA e SALVADORI (2006) e PACHECO e PAULA (1995). Foi realizado um cadastro controle onde os recipientes continham as seguintes informações: procedência, espécie identificada, substrato no qual foi coletado e data da triagem.

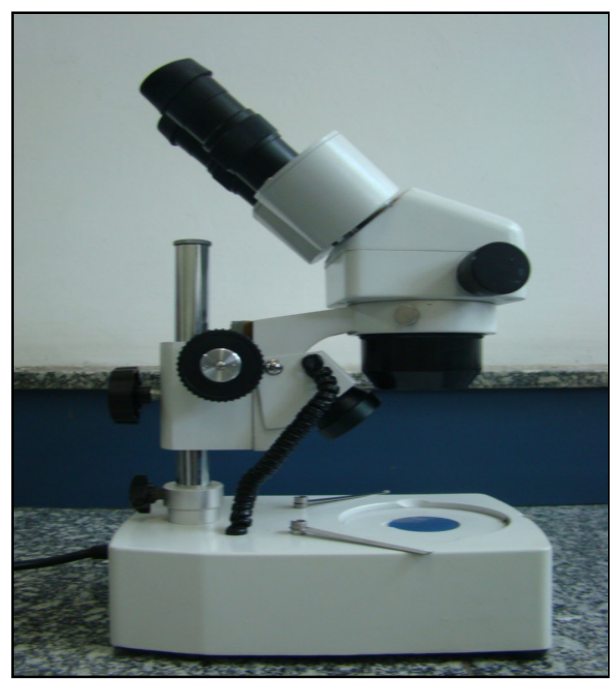

Figura 8 Lupa estereoscópica 
4.4 - Delineamento gráfico da reprodução dos insetos utilizados no experimento

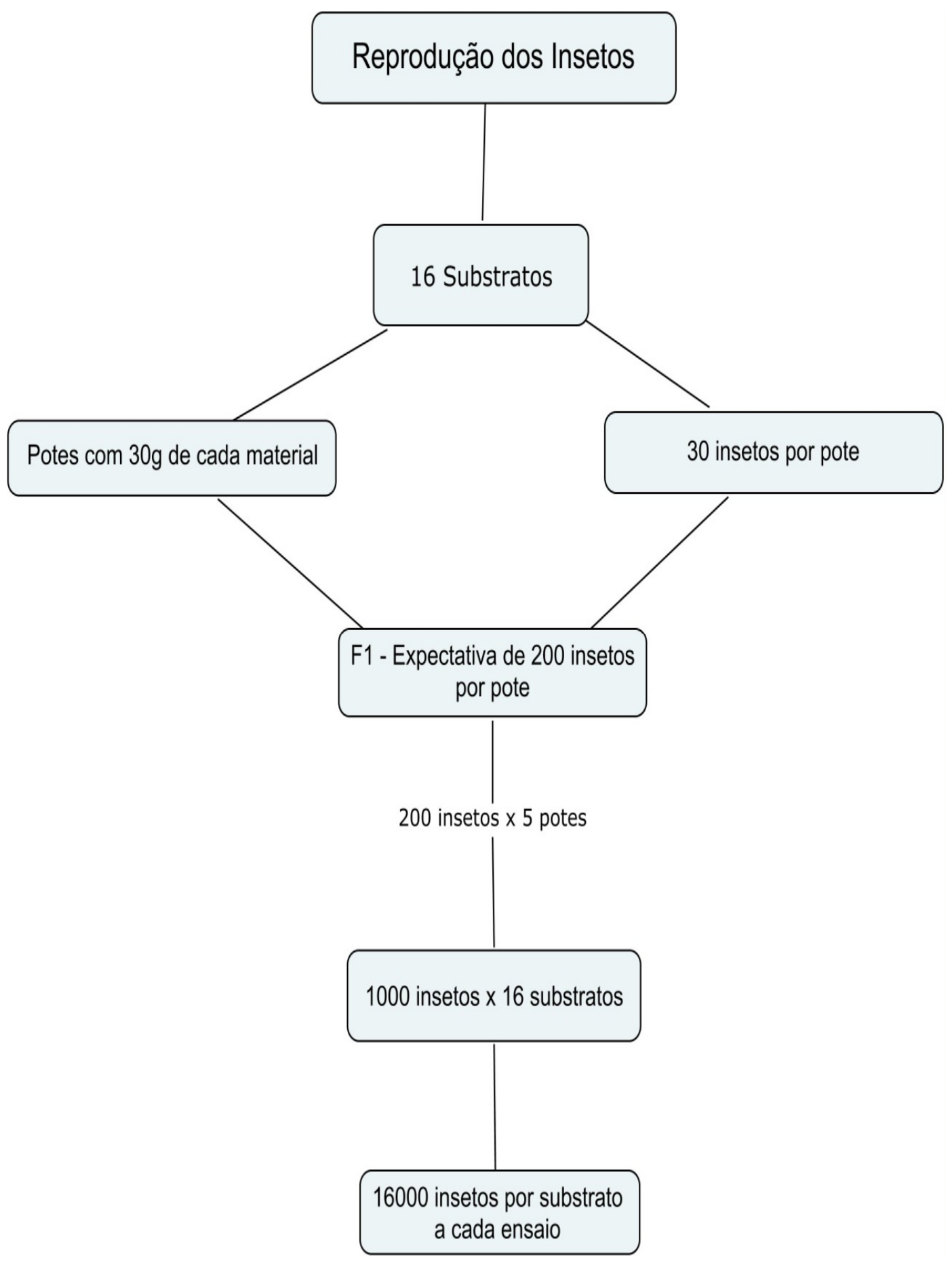




\section{5 - Ensaios de irradiação dos substratos}

Após a triagem dos materiais, foram selecionados os substratos que apresentaram infestação para posterior tratamento pelo processo de irradiação.

Foram confinados 20 adultos em $15 \mathrm{~g}$ com 5 repetições de cada material em recipientes plásticos de $10 \times 10 \mathrm{~cm}$ e mantidos durante 30 dias em sala climatizada $27 \pm 2{ }^{\circ} \mathrm{C}$ e umidade relativa de $70 \pm 5 \%$ afim de possibilitar a postura dos ovos. Em seguida, utilizando o Irradiador Multiprpósito Cobalto-60 com taxa de dose no período dos ensaios de $6 \mathrm{kGy} / \mathrm{h}$ as parcelas foram submetidas a doses crescentes de radiação gama de 0 (grupo controle); 0,25; 0,$50 ; 0,75 ; 1,00 ; 1,25 ; 1,50 ; 1,75$ e 2,00 kGy.

Quadro 4. Materiais infestados utilizados no bioensaio de irradiação dos materiais.

\begin{tabular}{|cc|}
\hline Espécie & Materiais infestados \\
\hline $\begin{array}{c}\text { Basioderma orellana (Colorífico), Capsicum } \\
\text { serricorne }\end{array}$ & $\begin{array}{c}\text { annuum (Páprica doce), Cassia } \\
\text { angustifólia (Sene), Coriandrum } \\
\text { sativum (Coentro), Mentha piperita } \\
\text { (Hortelã) e Petrosolium sativum } \\
\text { (Salsa) }\end{array}$ \\
& Petrosolium sativum (Erva doce), \\
& Mentha piperita (Hortelã), Petrosolium \\
& sativum (Salsa), Chamomilla recutita \\
(Camomila), Bixa orellana (Colorifico) & e Capsicum annuum (Páprica doce) \\
&
\end{tabular}




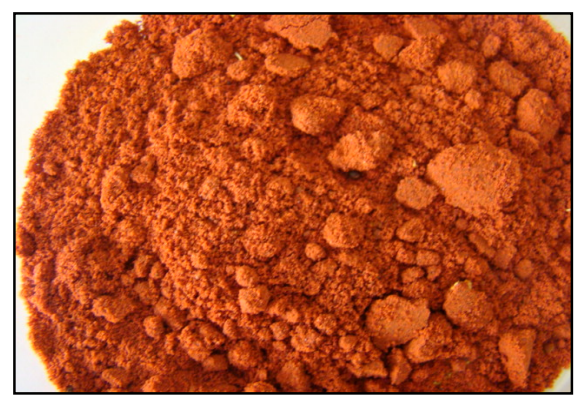

Figura 9. Colorifico (Bixa orellana)

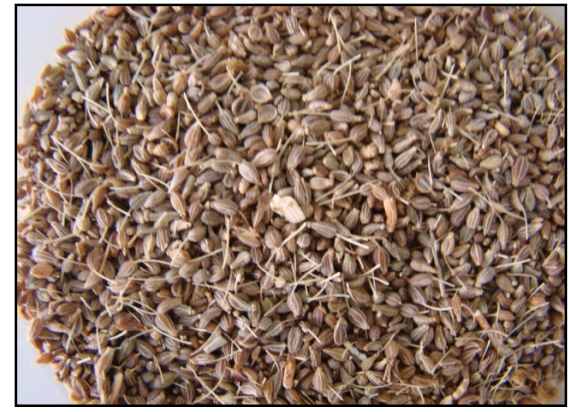

Figura 11. Erva doce (Pinpenella anisum)

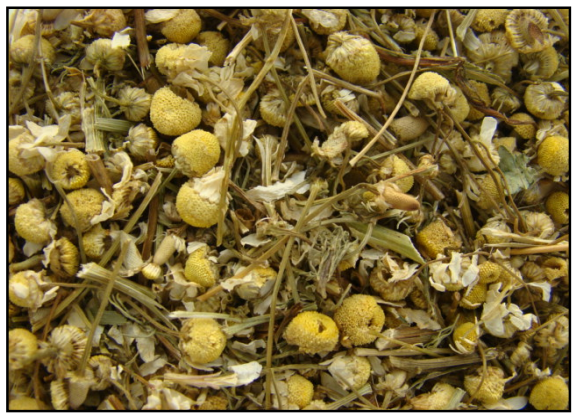

Figura 13. Camomila (Chamomila recutita)

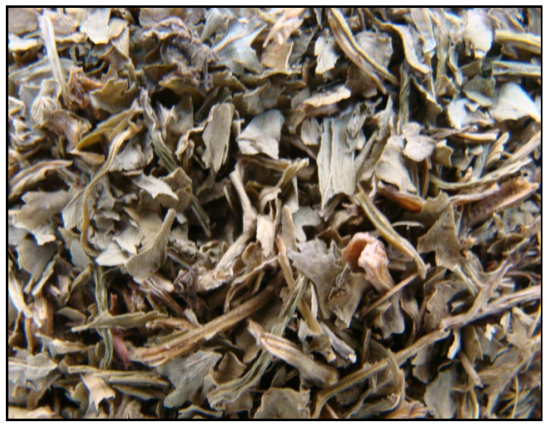

Figura 15. Coentro (Coriandrum sativum)

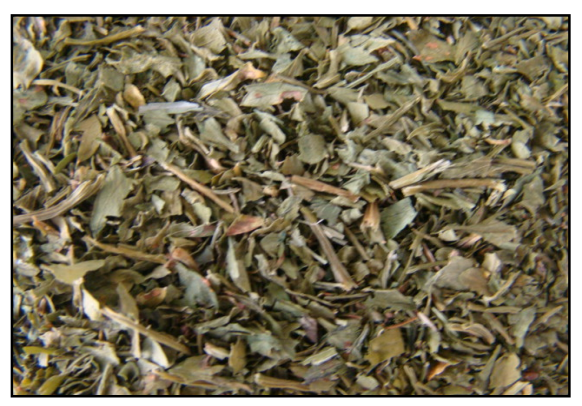

Figura 10. Salsa (Petroselium sativum)

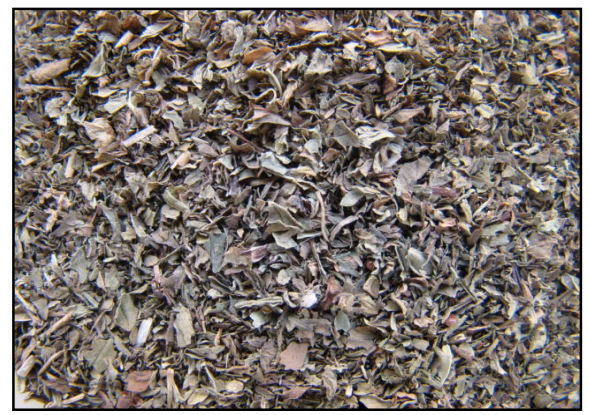

Figura 12. Hortelã (Mentha piperita)

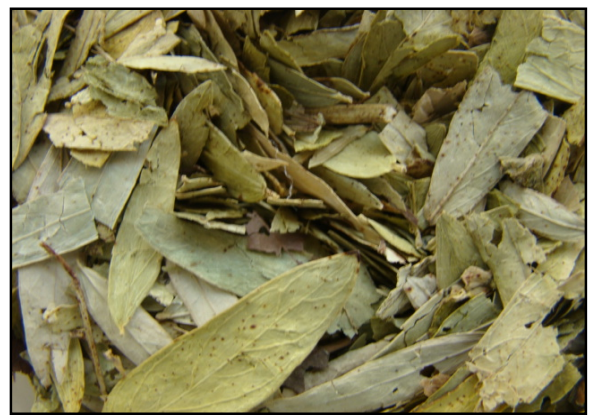

Figura 14. Sene (Cassia angustifolia)

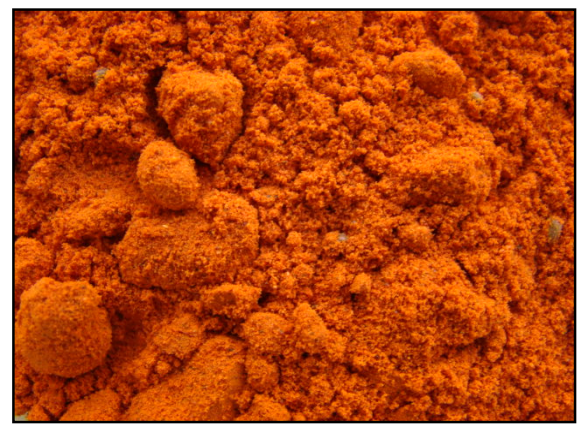

Figura 16. Páprica doce ( Capsisum annuum) 


\subsection{Determinação da dose letal de Sphaericus gibboides}

A determinação da dose letal imediata para adultos de Sphaericus gibboides, procedeu-se irradiando 4 repetições por tratamento contendo 25 indivíduos cada.

As doses utilizadas foram: 3,0;2,8;2,6;2,4;2,2;2,0;1,8;1,6;1,4;1,2; 1,0; 0,$8 ; 0,6$ kGy.

Os dados obtidos foram analisados através do teste de TUKEY onde as médias seguidas por letras distintas diferem entre si ao nível de significância indicado D.M.S. 5\%. 


\section{5- RESULTADOS E DISCUSSÃO}

\section{1 - Triagem dos materiais}

Na primeira triagem constatou-se que todos os materiais analisados não apresentaram presença de insetos adultos. Dos lotes analisadas Mentha piperita e Chamomila recutita apresentaram o maior índice de infestação, 40\% Pelmus boldus, Laurus nobilis, Capsicum annuum e Pimpinella anisum L., tiveram a maior diversidade de espécies encontradas, Baccharis trimera, Bixa orellana, Melissa officinalis, Origanum vulgares e Rosmarinus officinalis não apresentaram infestação (Tabela 1). A espécie Lasioderma serricorne apresentou maior número de indivíduos encontrados (942) (Tabela 3) e maior ocorrência nos diferentes materiais (68,75\%) (Tabela 2, Figura 21). Constatouse a presença de 898 imdividuos de Sphaericus gibboides em Chamomila recutita

Foi encontrado 1 indivíduo de Oryzaephilus sp. nos substratos Laurus nobilis e Pelmus boldus (Tabela 4), Cryptolestes sp. apresentou um indivíduo em Pimpinella anisum L (Tabela 5) e Ephestia sp. apresentou um indivíduo em Capsicum annuum (Tabela 6). Segundo IGLESIAS-ENRIQUE \& FRAGA (1998) produtos armazenados como os grãos, farelos, farinhas, frutas secas, especiarias, comumente são infestadas por pragas como traças (Plodia interpunctella), besouros (Lasioderma serricorne), ácaros entre outros depreciando visualmente e promovendo a deterioração do produto.

SANTOS (1993) mostra que o armazenamento prolongado só pode ser eficiente quando se adotam corretamente as práticas de colheita, limpeza, secagem e controle de insetos e fungos. Entretanto, as ervas e especiarias, devido aos métodos e princípios de controle inadequados em muitos casos acabam oferecendo para o comércio um alimento impróprio para consumo (VIZEU, 2004). As espécies identificadas neste levantamento são consideras pragas de produtos armazenados e de ampla distribuição pelo território nacional. Infestam uma grande variedade de produtos, como grãos, cereais, farelos, farinhas e produtos a base destes componentes. 
Tabela 1. Quantificação de insetos por substrato (\% total de infestação dos substratos nos diferentes lotes analisados).

\begin{tabular}{|c|c|c|c|c|}
\hline \multicolumn{2}{|c|}{ Substrato } & \multirow{2}{*}{$\begin{array}{c}\text { Espécie identificada* } \\
\text { Nome } \\
\text { científico }\end{array}$} & \multirow{2}{*}{$\begin{array}{l}\text { Quantida } \\
\text { de total } \\
\text { de } \\
\text { insetos }\end{array}$} & \multirow{2}{*}{$\begin{array}{l}\text { \% total de } \\
\text { infestação }\end{array}$} \\
\hline $\begin{array}{c}\text { Nome } \\
\text { científico }\end{array}$ & $\begin{array}{l}\text { Nome } \\
\text { popular }\end{array}$ & & & \\
\hline Mentha piperita & Hortelã & Lasioderma serricorne & 71 & 40 \\
\hline Cassia angustifolia & Sene & Lasioderma serricorne & 1 & 10 \\
\hline \multirow{3}{*}{ Pimpinella anisum $L$. } & & Cryptolestes sp. & 1 & 10 \\
\hline & Erva Doce & & & \\
\hline & & Lasioderma serricorne & 17 & 30 \\
\hline \multirow[t]{2}{*}{ Chamomila recutita } & Camomila & Sphaericus gibboides & 898 & 10 \\
\hline & & Lasioderma serricorne & 595 & 40 \\
\hline Petrosolium sativum & Salsa & Lasioderma serricorne & 3 & 10 \\
\hline \multirow{2}{*}{ Laurus nobilis } & Louro & Lasioderma serricorne & 1 & 10 \\
\hline & & Oryzaephilus sp. & 1 & 10 \\
\hline \multirow{3}{*}{ Capsicum annuum } & & Lasioderma serricorne & 208 & 20 \\
\hline & Páprica doce & & & \\
\hline & & Ephestia sp. & 1 & 10 \\
\hline Bixa orellana & Colorífico & - & - & - \\
\hline Ocimum basilicum & Manjericão & Lasioderma serricorne & 36 & 20 \\
\hline $\begin{array}{c}\text { Rosmarinus } \\
\text { officinalis }\end{array}$ & Alecrim & - & - & - \\
\hline \multirow{3}{*}{ Pelmus boldus } & & Lasioderma serricorne & 2 & 10 \\
\hline & Boldo & & & \\
\hline & & Oryzaephilus sp. & 1 & 10 \\
\hline Baccharis strimera & Carqueja & - & - & - \\
\hline Melissa officinalis & Erva Cidreira & - & - & - \\
\hline Origanum vulgare & Orégano & - & - & - \\
\hline Thymus vulgaris & Tomilho & Lasioderma serricorne & 7 & 10 \\
\hline Coriandrum sativum & Coentro & Lasioderma serricorne & 1 & 10 \\
\hline
\end{tabular}


Tabela 2. Número total de insetos (45 dias) e \% de infestação nos diferentes materiais provenientes de estabelecimentos atacadistas na cidade de São Paulo/SP

\begin{tabular}{cccccc}
\hline \multirow{2}{*}{ Ordem } & Família & Espécie & $\begin{array}{c}\text { Nome } \\
\text { popular }\end{array}$ & $\begin{array}{c}\mathbf{N}^{\circ} \text { total de } \\
\text { insetos }\end{array}$ & $\begin{array}{c}\text { \% de } \\
\text { infestação }\end{array}$ \\
\hline \multirow{2}{*}{ Coleoptera } & Anobiidae & $\begin{array}{c}\text { Lasioderma } \\
\text { serricorne }\end{array}$ & $\begin{array}{c}\text { Caruncho } \\
\text { do fumo }\end{array}$ & 942 & 68,75 \\
\cline { 2 - 6 } & Silvanidae & Oryzaephilus sp. & $\begin{array}{c}\text { Besouro da } \\
\text { cevada }\end{array}$ & 2 & 12,50 \\
\cline { 2 - 6 } & Laemophloeid & Cryptolestes sp. & Besouro & 1 & 6,25 \\
\hline ae & Ptinidae & $\begin{array}{c}\text { Sphaericus } \\
\text { gibboides }\end{array}$ & $\begin{array}{c}\text { Besouro } \\
\text { aranha }\end{array}$ & 898 & 6,25 \\
\hline Lepidoptera & Pyralidae & Ephestia sp. & $\begin{array}{c}\text { Traça dos } \\
\text { cereais }\end{array}$ & 1 & 6,25 \\
\hline
\end{tabular}

Figura 17. Porcentagem de infestação por espécie nos lotes analisados

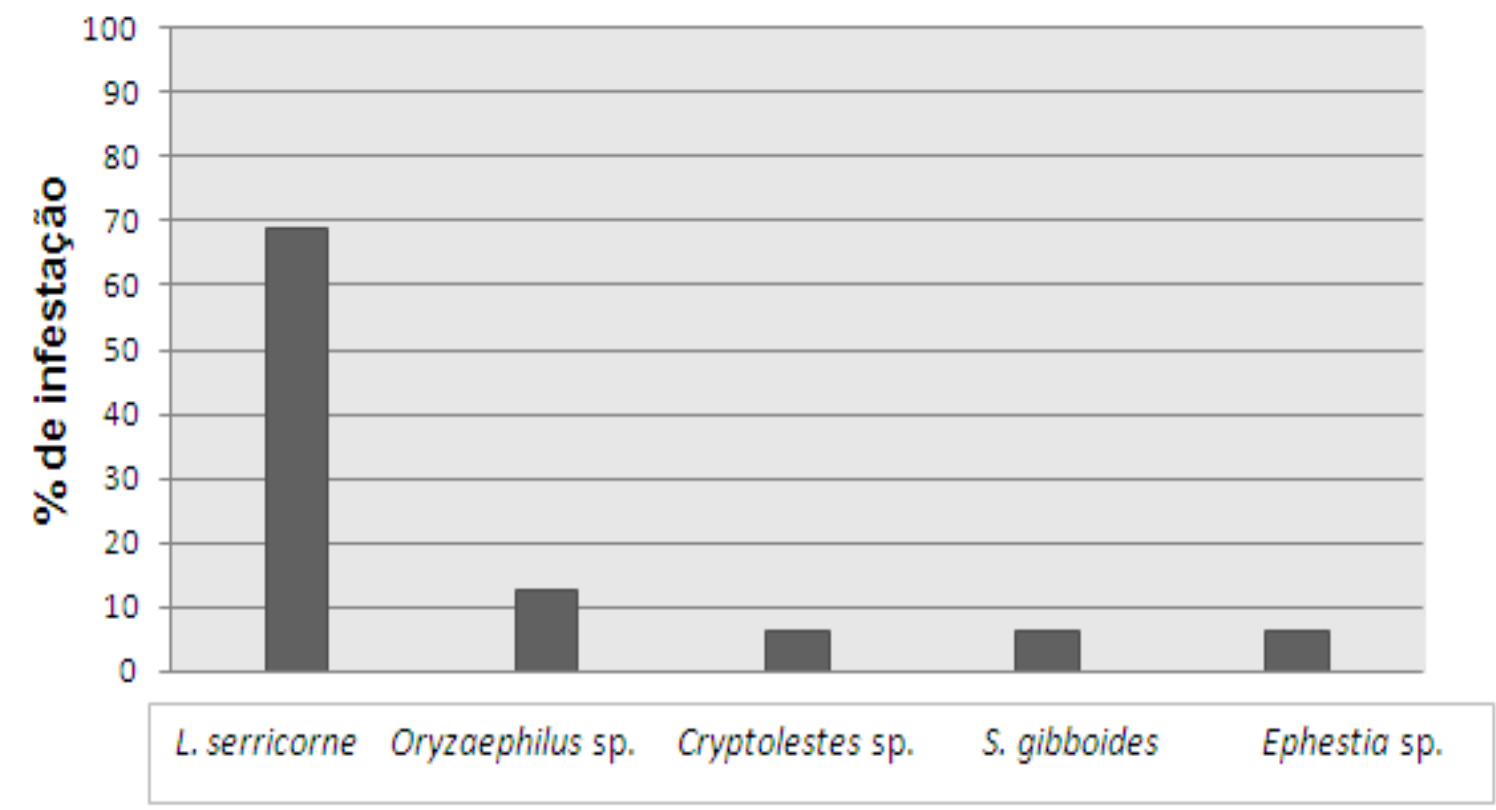


Tabela 3. Número de Oryzaephilus sp encontrados nos diferentes substratos, coletados no período de abril a novembro de 2011.

\begin{tabular}{|c|c|c|}
\hline Espécie & Substratos & $\begin{array}{c}\text { Número de insetos } \\
\text { por substrato }\end{array}$ \\
\hline & Laurus nobilis & 1 \\
\hline Figura 18. Oryzaephilus sp. & \multirow[t]{2}{*}{ Pelmus boldus } & \multirow[t]{2}{*}{1} \\
\hline Fonte: Padil.au. & & \\
\hline
\end{tabular}

Tabela 4. Número de Cryptolestes sp encontrados nos diferentes substratos, coletados no período de abril a novembro de 2011.

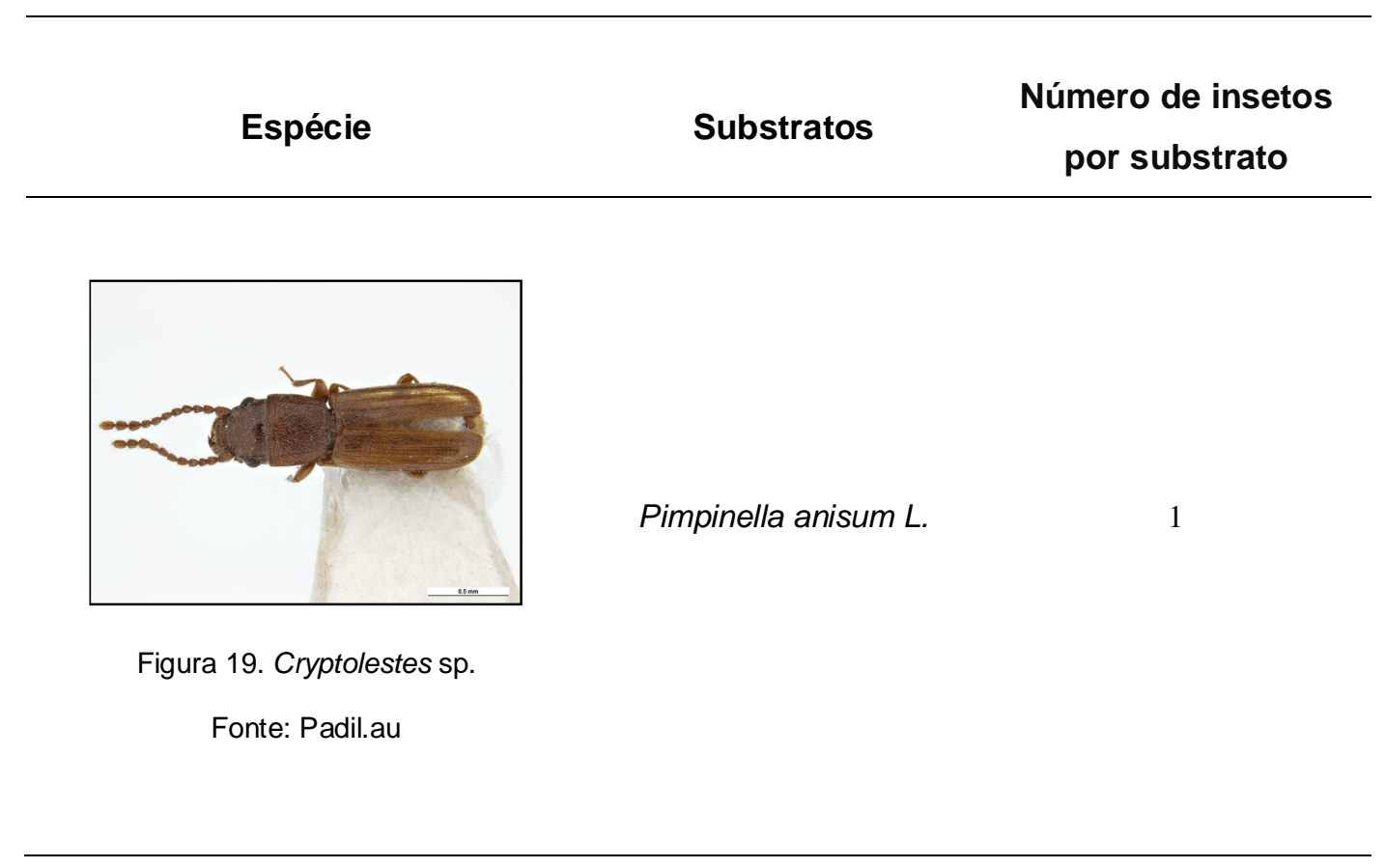


Tabela 5. Número de Ephestia sp encontradas nos diferentes substratos, coletadas no período de abril a novembro de 2011.

\begin{tabular}{|c|c|c|}
\hline Espécie & Substratos & $\begin{array}{c}\text { Número de insetos } \\
\text { por substrato }\end{array}$ \\
\hline
\end{tabular}

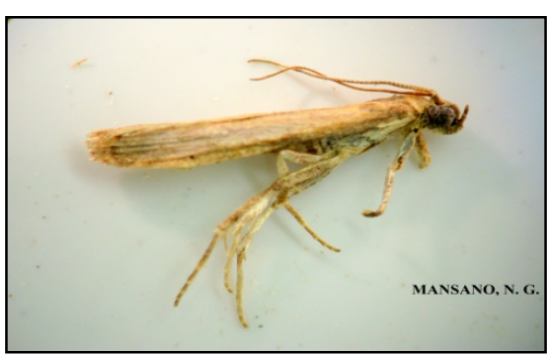

Capsicum annuum

1

Figura 20. Ephestia sp. Fonte:

MANSANO, N. G.

Tabela 6. Número de Sphaericus gibboides encontrados nos diferentes substratos, coletadas no período de abril a novembro de 2011.

\section{Espécie}

Substratos

Número de insetos por substrato

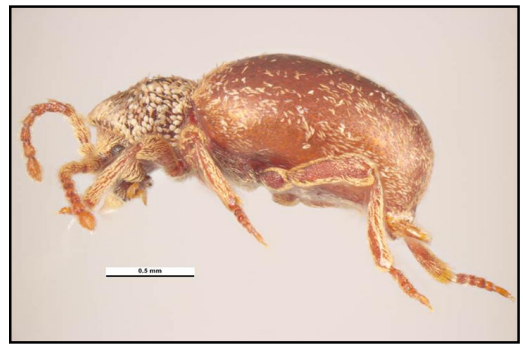

Figura 21 Sphaericus gibboides.

Fonte: Padil.au. 
Tabela 7. Número de Lasioderma serricorne encontradas nos diferentes substratos, coletadas no período de abril a novembro de 2011.

\begin{tabular}{|c|c|c|}
\hline Espécie & Substratos & $\begin{array}{l}\text { Número de insetos } \\
\text { por substrato }\end{array}$ \\
\hline \multirow{11}{*}{$\begin{array}{l}\text { Figura 22. Lasioderma serricorne. } \\
\text { Fonte: MANSANO, N. G. }\end{array}$} & Mentha piperita & 71 \\
\hline & Cassia angustifolia & 1 \\
\hline & Pimpinella anisum. & 17 \\
\hline & Chamomilla recutita & 595 \\
\hline & Petrosolium sativum & 3 \\
\hline & Laurus nobilis & 1 \\
\hline & Coriandrum sativum & 1 \\
\hline & Capsicum annuum & 208 \\
\hline & Ocimum basilicum & 36 \\
\hline & Pelmus boldus & 2 \\
\hline & Thymus vulgaris & 7 \\
\hline
\end{tabular}




\section{2 - Taxa de desenvolvimento de Lasioderma serricorne e Sphaericus gibboides}

Tabela 8. Número total e Média* de adultos emergidos de Lasioderma serricorne nos diferentes substratos. Março de 2012.

\begin{tabular}{|c|c|c|c|c|}
\hline Substrato & Repetições & $\begin{array}{c}\text { Número } \\
\text { total }\end{array}$ & Média* & $5 \%$ \\
\hline Chamomila recutita & 5 & 915 & 183 & $\mathrm{a}$ \\
\hline Petroselium sativum & 5 & 575 & 115 & $\mathrm{a}$ \\
\hline Pimpinella anisum & 5 & 440 & 88 & c \\
\hline Mentha piperita & 5 & 270 & 54 & $d$ \\
\hline Origanum vulgare & 5 & 240 & 48 & de \\
\hline Bixa orellana & 5 & 185 & 37 & ef \\
\hline Ocimum basilicum & 5 & 175 & 35 & ef \\
\hline Cassia angustifolia & 5 & 135 & 27 & $f$ \\
\hline Capsicum annuum & 5 & 120 & 24 & $f$ \\
\hline Coriandrum sativum & 5 & 65 & 13 & g \\
\hline $\begin{array}{c}\text { Rosmarinus } \\
\text { officinalis }\end{array}$ & 5 & - & - & $\mathrm{h}$ \\
\hline Melissa officinalis & 5 & - & - & $\mathrm{h}$ \\
\hline Laurus nobilis & 5 & - & - & $\mathrm{h}$ \\
\hline $\begin{array}{c}\text { Plectranthus } \\
\text { barbatus }\end{array}$ & 5 & - & - & $\mathrm{h}$ \\
\hline Thymus vulgaris & 5 & - & - & $\mathrm{h}$ \\
\hline \multirow[t]{2}{*}{ Baccharis trimera } & 5 & - & - & $\mathrm{h}$ \\
\hline & C.V. & & & 8,5 \\
\hline
\end{tabular}

- Médias seguidas por letras distintas diferem entre si ao nível de significância indicado D.M.S. $5 \%$. 
Tabela 9. Número total e Média* de adultos emergidos de Sphaericus gibboides nos diferentes substratos desidratado. Março de 2012.

\begin{tabular}{|c|c|c|c|c|}
\hline Substrato & Repetições & $\begin{array}{c}\text { Número } \\
\text { total }\end{array}$ & Média* & $5 \%$ \\
\hline Mentha piperita & 5 & 155 & 31 & a \\
\hline Chamomila recutita & 5 & 100 & 20 & $a b$ \\
\hline Petroselium sativum & 5 & 95 & 19 & $\mathrm{~b}$ \\
\hline Capsicum annuum & 5 & 90 & 18 & $b$ \\
\hline Pimpinella anisum & 5 & 65 & 13 & $\mathrm{~b}$ \\
\hline Bixa orellana & 5 & 60 & 12 & $b$ \\
\hline $\begin{array}{c}\text { Rosmarinus } \\
\text { officinalis }\end{array}$ & 5 & - & - & C \\
\hline Origanum vulgare & 5 & - & - & c \\
\hline Melissa officinalis & 5 & - & - & C \\
\hline Coriandrum sativum & 5 & - & - & c \\
\hline Cassia angustifolia & 5 & - & - & c \\
\hline Baccharis trimera & 5 & - & - & C \\
\hline Laurus nobilis & 5 & - & - & c \\
\hline $\begin{array}{c}\text { Plectranthus } \\
\text { barbatus }\end{array}$ & 5 & - & - & c \\
\hline Thymus vulgaris & 5 & - & - & C \\
\hline Ocimum basilicum & 5 & - & - & $C$ \\
\hline & C.V. & & & 4,6 \\
\hline
\end{tabular}

- Médias seguidas por letras distintas diferem entre si ao nível de significância indicado D.M.S. $5 \%$. 
Figura 23. Média de adulto emergidos de Lasioderma serricorne nos diferentes substratos.

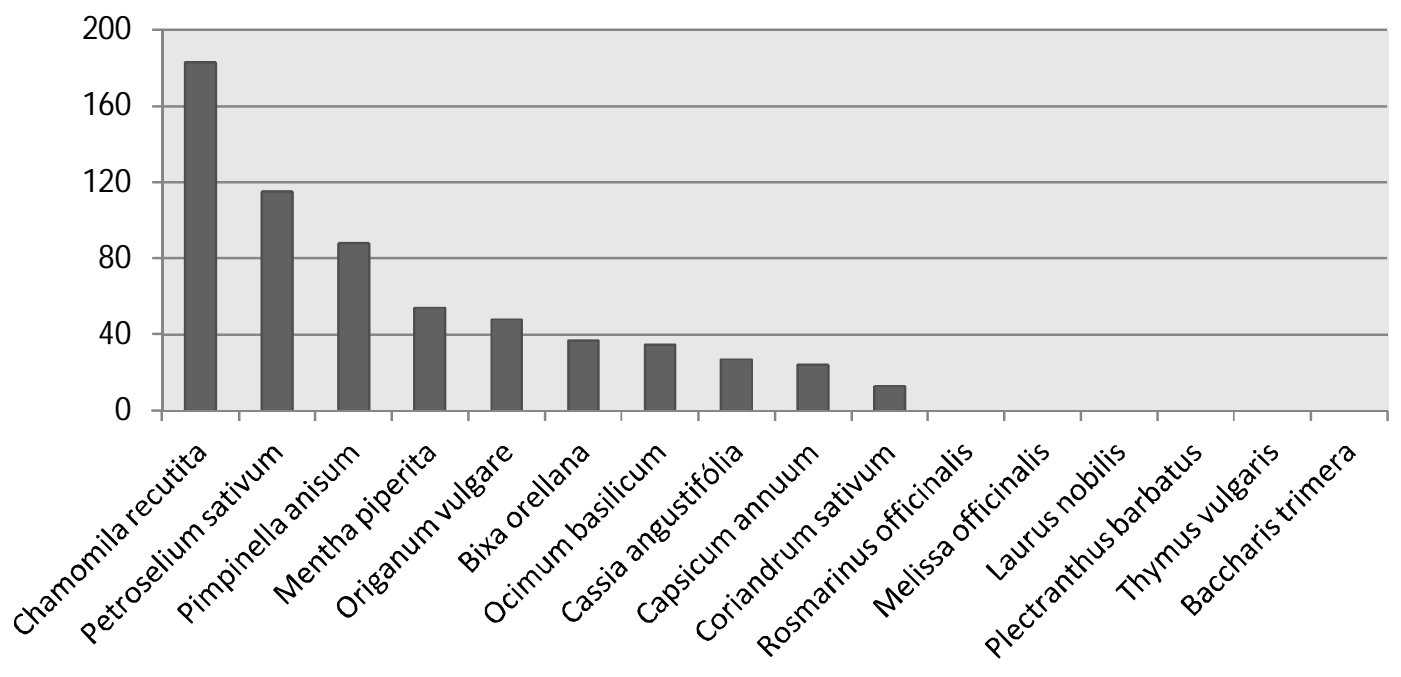

Figura 24. Média de adulto emergidos de Sphaericus gibboides nos diferentes substratos.

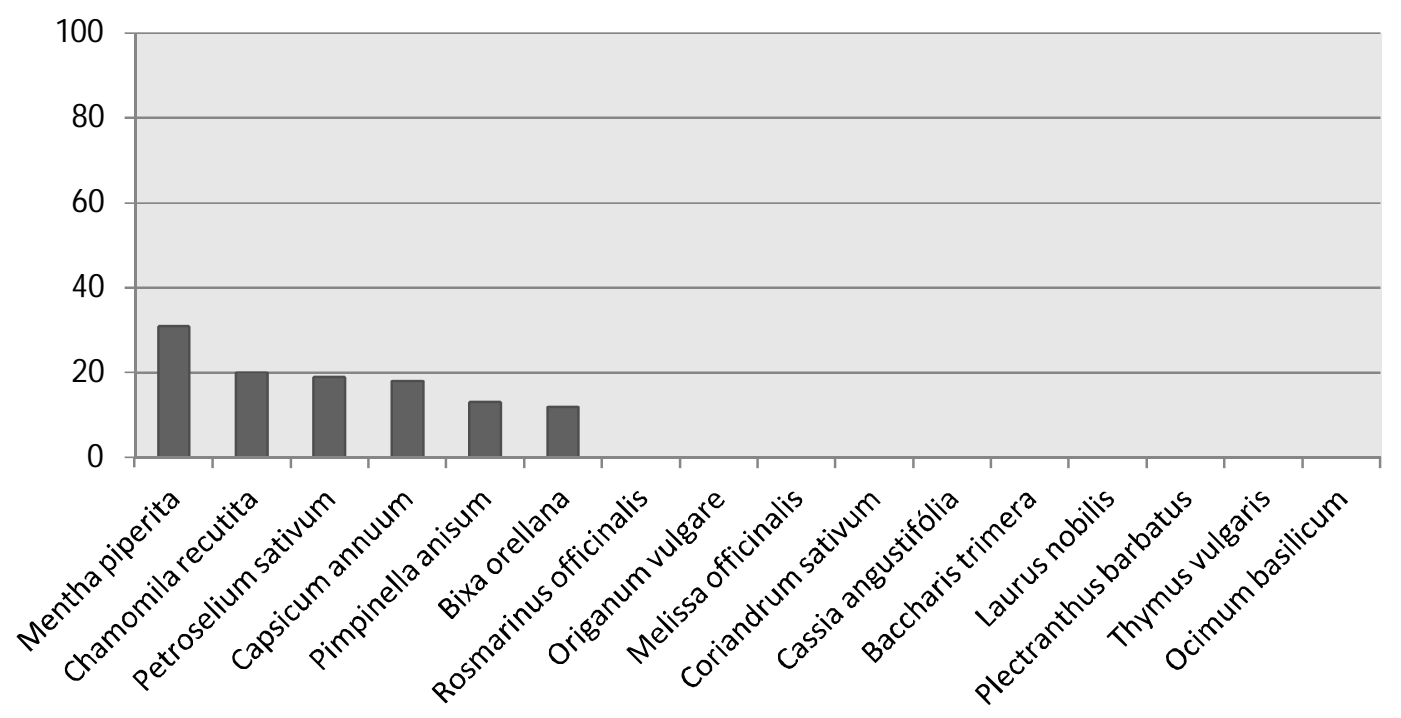

Pode-se verificar que, no final do período de 40 dias após a data de infestação, não foi observado à presença de indivíduos adultos de L. serricorne nos substratos Laurus nobilis, Plectranthus barbatus, Thymus vulgaris, Baccharis trimera e Rosmarinus officinalis. Os substratos Chamomila recutita e Petroselium 
sativum apresentaram em média 183,2 e 116 indivíduos adultos respectivamente. (Tabela 7, Figura 22).

MOREIRA et al. (2010) verificou que na temperatura de $30^{\circ} \mathrm{C}$ a longevidade dos adultos de $L$. serricorne foi de 15 a 21 dias em sorgo e milheto e de 12 a 14 dias em camomila. A duração do ciclo biológico, de larva a adulto, na temperatura de $30^{\circ} \mathrm{C}$, foi de 27,$1 ; 22,8$ e 27,1 dias para as dietas de sorgo, milheto e camomila, respectivamente.

Os valores obtidos por HOWE (1957), explicam que as diferenças na longevidade dos adultos estão relacionadas ao tipo de alimentação na fase larval, temperatura e a umidade relativa.

Os materiais infestados com $S$. gibboides que apresentaram maior média foram, Mentha piperita, Chamomila recutita com 30,8 e 20,6 respectivamente. Durante as avaliações não foram observados individuos adultos de S.gibboides em Laurus nobilis, Melissa officinalis, Baccharis trimera, Coriandrum sativum, Cassia angustifolia, Plectranthus barbatus e Ocimum basilicum (Tabela 8, Figura 23).

Esta espécie foi descrita por GRACE (1985) ocorrendo em produtos secos de origem vegetal tais como: Chamaecytisus prolifer, Vicia faba L., Capsicum annuum L. Pinus ponderosa. 


\section{3 - Irradiação dos materiais infestados com Lasioderma serricorne}

Tabela 10. Número total e média de adultos (Lasioderma serricorne) emergidos no substrato Bixa orellana (Colorífico) irradiados com doses crescentes de radiação gama. Agosto a Outubro de 2012

\begin{tabular}{cccccccccc}
\hline \multirow{2}{*}{ Parcelas } & \multicolumn{7}{c}{ Dose (kGy) } \\
& 0,00 & 0,25 & 0,50 & 0,75 & 1,00 & 1,25 & 1,50 & 1,75 & 2,00 \\
\hline 1 & 35 & - & - & - & - & - & - & - & - \\
2 & 30 & - & - & - & - & - & - & - & - \\
3 & 28 & - & - & - & - & - & - & - & - \\
4 & 34 & - & - & - & - & - & - & - & - \\
5 & 39 & - & - & - & - & - & - & - & - \\
\hline Média & 33,2 & - & - & - & - & - & - & - & - \\
\hline
\end{tabular}

Tabela 11. Número total e média de adultos (Lasioderma serricorne) emergidos no substrato Capsicum annuum (Páprica doce) irradiados com doses crescentes de radiação gama. Agosto a Outubro de 2012.

\begin{tabular}{cccccccccc}
\hline \multirow{2}{*}{ Parcelas } & 0,00 & 0,25 & 0,50 & 0,75 & 1,00 & 1,25 & 1,50 & 1,75 & 2,00 \\
\hline 1 & 28 & - & - & - & - & - & - & - & - \\
2 & 30 & - & - & - & - & - & - & - & - \\
3 & 32 & - & - & - & - & - & - & - & - \\
4 & 36 & - & - & - & - & - & - & - & - \\
5 & 42 & - & - & - & - & - & - & - & - \\
\hline Média & 33,6 & - & - & - & - & - & - & - & - \\
\hline
\end{tabular}


Tabela 12. Número total e média de adultos emergidos (Lasioderma serricorne) no substrato Cassia angustifolia (Sene) irradiados com doses crescentes de radiação gama. Agosto a Outubro de 2012.

\begin{tabular}{cccccccccc}
\hline Parcelas & & & \multicolumn{7}{c}{ Dose (kGy) } \\
& 0,00 & 0,25 & 0,50 & 0,75 & 1,00 & 1,25 & 1,50 & 1,75 & 2,00 \\
\hline 1 & 45 & - & - & - & - & - & - & - & - \\
2 & 33 & - & - & - & - & - & - & - & - \\
3 & 43 & - & - & - & - & - & - & - & - \\
4 & 31 & - & - & - & - & - & - & - & - \\
5 & 29 & - & - & - & - & - & - & - & - \\
\hline Média & 36,2 & - & - & - & - & - & - & - & - \\
\hline
\end{tabular}

Tabela 13. Número total e média de adultos (Lasioderma serricorne) emergidos no substrato Coriandrum sativum (Coentro) irradiados com doses crescentes de radiação gama. Agosto a Outubro de 2012.

\begin{tabular}{cccccccccc}
\hline Parcelas & 0,00 & 0,25 & 0,50 & 0,75 & 1,00 & 1,25 & 1,50 & 1,75 & 2,00 \\
\hline 1 & 55 & - & - & - & - & - & - & - & - \\
2 & 48 & - & - & - & - & - & - & - & - \\
3 & 67 & - & - & - & - & - & - & - & - \\
4 & 50 & - & - & - & - & - & - & - & - \\
5 & 53 & - & - & - & - & - & - & - & - \\
\hline Média & 54,6 & - & - & - & - & - & - & - & - \\
\hline
\end{tabular}

Tabela 14. Número total e média de adultos (Lasioderma serricorne) emergidos no substrato Mentha piperita (Hortelã) irradiados com doses crescentes de radiação gama. Agosto a Outubro de 2012.

\begin{tabular}{cccccccccc}
\hline Parcelas & 0,00 & 0,25 & 0,50 & 0,75 & 1,00 & 1,25 & 1,50 & 1,75 & 2,00 \\
\hline 1 & 39 & - & - & - & - & - & - & - & - \\
2 & 43 & - & - & - & - & - & - & - & - \\
3 & 45 & - & - & - & - & - & - & - & - \\
4 & 37 & - & - & - & - & - & - & - & - \\
5 & 50 & - & - & - & - & - & - & - & - \\
\hline Média & 42,8 & - & - & - & - & - & - & - & - \\
\hline
\end{tabular}


Tabela 15. Número total e média de adultos de (Lasioderma serricorne) emergidos no substrato Petrosolium sativum (Salsa) irradiados com doses crescentes de radiação gama. Agosto a Outubro de 2012.

\begin{tabular}{cccccccccc}
\hline Parcelas & 0,00 & 0,25 & 0,50 & 0,75 & 1,00 & 1,25 & 1,50 & 1,75 & 2,00 \\
\hline 1 & 75 & - & - & - & - & - & - & - & - \\
2 & 68 & - & - & - & - & - & - & - & - \\
3 & 59 & - & - & - & - & - & - & - & - \\
4 & 63 & - & - & - & - & - & - & - & - \\
5 & 60 & - & - & - & - & - & - & - & - \\
\hline Média & 65 & - & - & - & - & - & - & - & - \\
\hline
\end{tabular}

Verificou-se que a dose de radiação gama para não emergência de adultos provenientes de ovos e larvas nos substratos Bixa orellana (Tabela 9), Capsicum annuum (Tabela 10), Cassia angustifolia (Tabela 11), Coriandrum sativum (Tabela 12), Mentha piperita (Tabela 13) e Petrosolium sativum (Tabela 14) foi de 0,25 kGy. Não foi observada a presença de adultos nas demais doses crescentes.

Arthur (2002) verificou que a dose de radiação gama de 0,5 kGy foi suficiente para induzir a esterilização e consequentemente a desinfestação de rações infestadas por $L$. serricorne, P.interpuctella, Sitophilu zeamais e Sitophilus oryzae. 


\section{4 - Irradiação dos materiais infestados com Sphaericus gibboides.}

Tabela 16. Número total e média de adultos (Sphaericus gibboides) emergidos no substrato Capsicum annuum (Páprica doce) irradiados com doses crescentes de radiação gama. Agosto a Outubro de 2012.

\begin{tabular}{cccccccccc}
\hline Parcelas & 0,00 & 0,25 & 0,50 & 0,75 & 1,00 & 1,25 & 1,50 & 1,75 & 2,00 \\
\hline 1 & 25 & - & - & - & - & - & - & - & - \\
2 & 17 & - & - & - & - & - & - & - & - \\
3 & 15 & - & - & - & - & - & - & - & - \\
4 & 23 & - & - & - & - & - & - & - & - \\
5 & 24 & - & - & - & - & - & - & - & - \\
\hline Média & 20,8 & - & - & - & - & - & - & - & - \\
\hline
\end{tabular}

Tabela 17 Tabela 12 - Número total e média de adultos (Sphaericus gibboides) emergidos no substrato Mentha piperita (Hortelã) irradiados com doses crescentes de radiação gama. Agosto a Outubro de 2012.

\begin{tabular}{cccccccccc}
\hline \multirow{2}{*}{ Parcelas } & & & \multicolumn{7}{c}{ Dose (kGy) } \\
& 0,00 & 0,25 & 0,50 & 0,75 & 1,00 & 1,25 & 1,50 & 1,75 & 2,00 \\
\hline 1 & 28 & - & - & - & - & - & - & - & - \\
2 & 29 & - & - & - & - & - & - & - & - \\
3 & 35 & - & - & - & - & - & - & - & - \\
4 & 24 & - & - & - & - & - & - & - & - \\
5 & 33 & - & - & - & - & - & - & - & - \\
\hline Média & 29,8 & - & - & - & - & - & - & - & - \\
\hline
\end{tabular}


Tabela 18. Número total e média de adultos (Sphaericus gibboides) emergidos no substrato Bixa orellana (Colorífico) irradiados com doses crescentes de radiação gama. Agosto a Outubro de 2012.

\begin{tabular}{cccccccccc}
\hline \multirow{2}{*}{ Parcelas } & 0,00 & 0,25 & 0,50 & 0,75 & 1,00 & 1,25 & 1,50 & 1,75 & 2,00 \\
\hline 1 & 23 & - & - & - & - & - & - & - & - \\
2 & 19 & - & - & - & - & - & - & - & - \\
3 & 10 & - & - & - & - & - & - & - & - \\
4 & 14 & - & - & - & - & - & - & - & - \\
5 & 12 & - & - & - & - & - & - & - & - \\
\hline Média & 15,6 & - & - & - & - & - & - & - & - \\
\hline
\end{tabular}

Tabela 19. Número total e média de adultos (Sphaericus gibboides) emergidos no substrato Chamomila recutita (Camomila) irradiados com doses crescentes de radiação gama. Agosto a Outubro de 2012.

\begin{tabular}{cccccccccc}
\hline \multirow{2}{*}{ Parcelas } & 0,00 & 0,25 & 0,50 & 0,75 & 1,00 & 1,25 & 1,50 & 1,75 & 2,00 \\
\hline 1 & 17 & - & - & - & - & - & - & - & - \\
2 & 30 & - & - & - & - & - & - & - & - \\
3 & 18 & - & - & - & - & - & - & - & - \\
4 & 16 & - & - & - & - & - & - & - & - \\
5 & 23 & - & - & - & - & - & - & - & - \\
\hline Média & 20,8 & - & - & - & - & - & - & - & - \\
\hline
\end{tabular}

Tabela 20. Número total e média de adultos (Sphaericus gibboides) emergidos no substrato Pimpinella anisum (Erva doce) irradiados com doses crescentes de radiação gama. Agosto a Outubro de 2012.

\begin{tabular}{cccccccccc}
\hline \multirow{2}{*}{ Parcelas } & 0,00 & 0,25 & 0,50 & 0,75 & 1,00 & 1,25 & 1,50 & 1,75 & 2,00 \\
\hline 1 & 12 & - & - & - & - & - & - & - & - \\
2 & 13 & - & - & - & - & - & - & - & - \\
3 & 16 & - & - & - & - & - & - & - & - \\
4 & 12 & - & - & - & - & - & - & - & - \\
5 & 13 & - & - & - & - & - & - & - & - \\
\hline Média & 13,5 & - & - & - & - & - & - & - & - \\
\hline
\end{tabular}


Tabela 21. Número total e média de adultos (Sphaericus gibboides) emergidos no substrato Petrosolium sativum (Salsa) irradiados com doses crescentes de radiação gama. Agosto a Outubro de 2012.

\begin{tabular}{cccccccccc}
\hline Parcelas & 0,00 & 0,25 & 0,50 & 0,75 & 1,00 & 1,25 & 1,50 & 1,75 & 2,00 \\
\hline 1 & 10 & - & - & - & - & - & - & - & - \\
2 & 22 & - & - & - & - & - & - & - & - \\
3 & 24 & - & - & - & - & - & - & - & - \\
4 & 11 & - & - & - & - & - & - & - & - \\
5 & 19 & - & - & - & - & - & - & - & - \\
\hline Média & 17,2 & - & - & - & - & - & - & - & - \\
\hline
\end{tabular}

Os materiais Capsicum annuum (Tabela 15), Mentha piperita (Tabela 16), Bixa orellana (Tabela 17), Chamomila recutita (Tabela 18), Pimpinella anisum (Tabela 19) e Petrosolium sativum (Tabela 20) nas doses de 0,25; 0,50; 0,$75 ; 1,00 ; 1,25 ; 1,50 ; 1,75$ e 2,00 kGy não apresentaram emergência de adultos.

MEHTA et al. (1990) Pesquisaram os efeitos da radiação gama no desenvolvimento de Tribolium castaneum (Herbst.), após a irradiação de larvas, verificaram que a dose de 0,5 kGy foi Suficiente para inibir completamente a emergência de adultos e que as doses de 0,2 a 0,4 kGy prolongou o período Larval e atrasou a pupação. 


\subsection{Determinação da dose letal imediata para Sphaericus gibboides}

Tabela 22 - Avaliação da eficiência de dose crescentes de radiação gama $\left({ }^{60} \mathrm{CO}\right)$ sobre adultos de Sphaericus gibboides. Mortalidade por dose (Média*) e porcentagem de eficiência $\left(\% \mathrm{Ef}^{\star *}\right)$. São Paulo, Março de 2013.

\begin{tabular}{ccccc}
\hline Dose (kGy) & Repetições & Média $^{*}$ & $5 \%$ & $\%^{* f^{* *}}$ \\
\hline 3,0 & 4 & 25 & $\mathrm{a}$ & 100 \\
2,8 & 4 & 25 & $\mathrm{a}$ & 100 \\
2,6 & 4 & 25 & $\mathrm{a}$ & 100 \\
2,4 & 4 & 25 & $\mathrm{a}$ & 100 \\
2,2 & 4 & 25 & $\mathrm{a}$ & 100 \\
2,0 & 4 & 20 & $\mathrm{a}$ & 80 \\
1,8 & 4 & 20 & $\mathrm{a}$ & 80 \\
1,6 & 4 & 19 & $\mathrm{a}$ & 76 \\
1,4 & 4 & 5 & $\mathrm{~b}$ & 20 \\
1,2 & 4 & 2 & $\mathrm{c}$ & 8 \\
1,0 & 4 & - & $\mathrm{d}$ & - \\
0,8 & 4 & - & $\mathrm{d}$ & - \\
0.6 & 4 & - & $\mathrm{d}$ & - \\
0.0 & 4 & - & $\mathrm{d}$ & - \\
\hline
\end{tabular}

As doses de 1,0; 0,8 e 0,6 kGy não causaram mortalidade em adultos de S. gibboides. A média de mortalidade das doses de 2,0; 1,8; 1,6; 1,4 e 1,2 foram de 19,9; 19,6; 18,7; 4,6 e 1,4 kGy respectivamente. A aplicação das doses de 3,$0 ; 2,8 ; 2,6 ; 2,4$ e 2,2 kGy apresentou $100 \%$ de mortalidade dos indivíduos.

HUQUE (1963) irradiou adultos de Rhyzopertha dominica (Fabr.), Trubolium castaneum (Herbst.), Sitophilus granarius (L.), Trubolium granarium (Ervest.), obtendo 100\% de mortalidade após exposição a dose de 2,5kGy, 


\section{CONCLUSÕES}

O levantamento da entomofauna associada às plantas medicinais condimentares e aromáticas adquiridas no comercio varejista da cidade de São Paulo demonstrou que os substratos Mentha piperita, Cassia angustifolia, Capsicum annuum, Chamomila recutita, Petrosolium sativum, Laurus nobilis, Ocimum basilicum, Plectranthus barbatu e Thymus vulgaris estavam infestados por L. serricorne, representam 68,75\% das amostras coletadas.

Laurus nobilis e Plectranthus barbatus apresentaram 1 indivíduo de Oryzaephilus sp cada, representando $12,50 \%$ dos materiais.

Foi encontrado 1 indivíduo de Cryptolestes sp e Ephestia $\mathrm{sp}$ em Pimpinella anisum e Capsicum annuum, representado 6,25\% de infestação respectivamente.

A dose de 0,25 kGy foi eficiente na desinfestação de formas jovens de $L$. serricorne e S. gibboides, utilizando-se um Irradiador Multipropósito Cobalto-60 com taxa de dose de $6 \mathrm{KGy} / \mathrm{h}$.

A dose de 2,2 kGy apresentou $100 \%$ de letalidade imediata para adultos de S. gibboides. 


\section{REFERÊNCIAS BIBLIOGRÁFICAS}

ABIFISA - Associação Brasileira das Empresas do Setor Fitoterápico, Suplemento Alimentar e de Promoção da Saúde. Disponível em: < http://www.abifisa.org.br >. Acesso em: 15-06- 2012.

ARTHUR, V. Influência da Radiação Gama na longevidade de lagarta de Plodia interpunctella (Hubner,1813) (Lepdoptera-Pyralidae) em dieta artificial. Energia Nuclear na Agricultura, Piracicaba, v. 9, p. 28-35, 1988.

ARTHUR, Paula Bergamin. Emprego da radiação gama do Cobalto-60 na desinfestação de alguns tipos de rações para alimentação de animais de pequeno porte. 2012. Dissertação (Mestrado em Tecnologia Nuclear Aplicações) - Instituto de Pesquisas Energéticas e Nucleares, Universidade de São Paulo, São Paulo, 2012. Disponível em: $<$ http://www.teses.usp.br/teses/disponiveis/85/85131/tde-07032013-091659/>. Acesso em: 2013-06-04.

ARTHUR, V.; WIENDL, F. M.; PACHECO, J.M.; WALDER, J.M.M.; SCRILLO, R.B. Mortalidade e reprodução de Sitophiluszeamais, Mots. Em macarrão irradiado. Uso y calibracion de fuentes intensas de radiacion, p. 18-22 1973.

ASHWORTH, J. R. The biology of Lasioderma serricorne. Journal Stored Products. Res, vol. 29, n. 4, p. 291-303, 1993.

ALVES, S.B.; VENDRAMI, J.D; MARCHINI, L.C.; LOPES, J.R.S.; OMOTO, C. Entomologia agrícola. Piracicaba: FEALQ, 2002. 
AZEVEDO, C.D. et al.Cultivo Orgânico de Plantas Medicinais da Família LABIATAE (LAMIACEAE) sob Telado na Estação Experimental de Seropédica da PESAGRO-RIO. In: I CONGRESSO BRASILEIRO DE AGROBIOLOGIA, IV SEMINÁRIO INTERNACIONAL SOBRE AGROECOLOGIA, V SEMINÁRIO SOBRE AGROECOLOGIA, 1., 2003. Porto Alegre. Anais...Rio Grande do Sul: PUCRS, 2003.

BANKS, H.J.; FIELDS, P.G. Physical methods for insects control. Storage grain ecosystems . p. 353-409, 1995.

BOTSARIS, S. Fitoterapia Chinesa e Plantas Brasileiras. Ícone, 1995.

ANVISA. AGÊNCIA NACIONAL DE VIGILÂNCIA SANITÁRIA Resolução oำ 21, de 26 janeiro 2001. Disponível em: < http://anvisa.gov.Br/legis/resol/21_01rdc.htm > Acesso em: 24 jan. 2013.

CAMPOS, T. B.; ZORZENON, F. J. Boletim técnico: Pragas dos grãos e produtos armazenados. Instituto Biológico. São Paulo. no 17, p. 47. 2006.

CENA - Centro de Energia Nuclear na Agricultura da Universidade de São Paulo. Disponível em: < http://www.cena.usp.br/irradiacao/index.asp >. Acesso em: 07 jan. 2013.

CROWSON, R. A. The biology of the Coleoptera. London; New York: Academic Press, 1981.

EDDE, P. A.; EATON, M.; KELLS. S. A.; PHILLIPS. E. W. Biology, Behavior, and Ecology of Pests in Other Durable Commodities. Chapter 5. Stored Product Protection. K-State Research and Extension. Kansas, EUA. p. 1-62, 2012. 
EMBRARAD , <http://www.embrarad.com.br/alimentos> Acesso em 03 de jan. de 2013.

FAO/IAEA. Division of Nuclear Techniques in Food and Agriculture International Atomic Energy Agency. Facts About Food Irradiation. 1999. Disponível em < http://www.iaea.org/icgfi/documents/foodirradiation.pdf >. Acesso em 27 jul. 2012.

FIORENZE, R. Armazenamento de Alimentos. ALDRIGUE, M. L. Aspectos da Ciência e Tecnologia de Alimentos. Editora Universitária/ldéia. Volume 01. João Pessoa: Editora Universitária/ldéia, 2002. p.11-57.

FITOTERAPIA. Entre o conhecimento popular e o científico. Disponível em: < http://www.comciencia.br/reportagens/fito/fito1.htm >. Acesso em: 25 abr. 2012.

GALLO, D.; NAKANO, O.; SILVEIRA NETO, S.; CARVALHO, R. P. L.; BATISTA, G. C. de; BERTI FILHO, E.; PARRA, J. R. P.; ZUCCHI, R. A.; ALVES, S. B.; VENDRAMI, J.D. Manual de entomologia agrícola. 2.ed. São Paulo: Agronômica Ceres, 2002.

GIACOMETTI, D. C. Ervas condimentares e especiarias. São Paulo, SP. Nobel, 1989.

GULLAN, P.J.; CRANSTON, P.S. The insects: an outline of entomology. 1.ed. London: Chapman \& Hall, 1994.

GRACE, J. K. A spider beetle, Sphaericus gibboides Boieldieu (Coleoptera, Ptinidae), tunneling in wood in service. Pan-Pacific Entomologist, San Francisco, p. 288-290, 1998. 
HOUSSAIN, M. M.; BROWER, J. H.; TILTON, E. W. Sensitivity to an acute gamma radiation exposure of successively irradiated generations of the cowpea weevil. Journal of Economic. Entomology, v. 65, n. 6, p.1566-1568, 1972.

HUQUE, H. Preliminary studies on irradiation of some commom stored grain insects in Pakistan. Radiation and Radioisotopes Applied to Insects of Agricultural Importance. Proceedings of a Symposium, Athens, Vienna, IAEA. 455-63, 1963.

IGLESIAS-ENRIQUE, I.; FRAGA, R. Suitable packagingand stored methods for post harvest preservation of garlic irradiated and unirradiated. Cuba. Alimentaria, v. 35, n. 295, p. 92-96, 1998.

JUNIOR, V. F. V.; PINTO. A. C.; MACIEL, M. A. M. Plantas mediciais: Cura segura? . Química nova, São Paulo, v. 28, n. 3, 2005.

KUCEROVÁ, Z.; STEJSKAL, V. 2010. External egg morphology of two storedproduct anobiids, Stegobium paniceum and Lasioderma serricorne (Coleoptera: Anobiidae). Journal of Stored Products Research, vol. 46, p. 202-205.

LEAL, A.S., KRAMBROCK, K., RODRIGUES, R.R., Ressonância Paramagnética Eletrônica - RPE aplicada a análise de especiarias irradiadas (com radiação gama), Ciência e Tecnologia de Alimentos. V.24, PP.427-430, 2004.

LEE, E.J.; AHN, D.U. Production of Volatiles from Fatty Acids and Oils by Irradiation. Journal Food Science, p. 70-75, 2003. 
LIMA, J. O. G.; VILELA, E. F.; ZANUNCIO, J. C. Controle de Pragas. Viçosa, MG, p. 62. 1979.

LORINI, I.; MIIKE L.H; SCUSSEL, V.M. Armazenagem de grãos. Campinas. IBG. 2002.

MARINO, M.; Bersani, C.; Comi, G. Impedance measurements to study the antimicrobial activity of essential oils from Lamiaceae and Compositae.

International Journal of Food Microbiology. v.67: p. 187-195, 2001.

MEHTA, V.K.; SETHI, G.R.; GARG, A.K. Development of Tribolium castaneum (Herbst.) larvae after gamma irradiation of eggs. Journal of Nuclear Agricultural and Biology, New Delhi, p. 54-7. 1990.

MORGAN, R. Enciclopédia das ervas e plantas medicinais. São Paulo, S.P.: Hemus, 1994.

OLIVEIRA, L.C. Present situation of food irradiation in South America and the regulatory perspectives for Brazil. Radiation Physics and Chemistry, v.57, p. 249-252, 2000.

PACHECO, I. A.; PAULA, D. C. 1995. Insetos de grãos armazenados Identificação e biologia. Fundação Cargill. Campinas, 228p.

PAULA, N. Guia A-Z de Plantas: condimentos. São Paulo: Bei Comunicações, 2003. 
PERIOTO, N.W. Pragas Quarentenárias. Reunião Itinerante de Fitossanidade do Instituto Biológico, 26 a 29 de jun. 2001. Anais da IV Reunião itinerante de fitossanidade do Instituto Biológico, Ribeirão Preto: Instituto Biológico, p. 100103, 2005.

PINTO, A. C.; SILVA, D. H. S.; BOLZANI, V. S.; LOPES, N. P.; EPIFANIO, R. A. Produtos naturais: atualidade, desafios e perspectives. Química Nova, v. 25, p. 45-61, 2002.

POWELL, T. E. An ecological study of the tobacco beetle, Lasioderma serricorne Fabr., with special references to its lifehistory and control. Ecological Monographs, p. 333-393. 1931.

RESURRECCION, A.V.A, GALVEZ, F.C.F., FLETCHER, S.M., MISRA, S.K. Consumers attitudes towards irradiated food: results of a new study. Journal of Food Protection, v. 58, n. 2, p. 193-196, 1995.

RUSSOMANNO O.M.R.; KRUPPA P.C.. DOENÇAS FÚNGICAS DAS PLANTAS MEDICINAIS, AROMÁTICAS E CONDIMENTARES - PARTE AÉRE. Biológico, São Paulo, v.72, n.1, p.31-37, jan./jun., 2010 FUZÉR, L.; SOUZA, I. IBAMA dá início a núcleo de plantas medicinais. Bionotícias, Rio de Janeiro, n. 57, p.6-7, jan./fev. 2003.

SANTOS, J. P dos. Perdas Causadas por Insetos em Grãos Armazenados. SIMPÓSIO DE PROTEÇÃO DE GRÃOS ARMAZENADOS. 29 nov. - 01 dez, 1993, Passo Fundo. Anais.Passo Fundo: EMBRAPA-CNTP, p. 9 -22. 1993.

VIZEU, D. M. Solução para contaminação ou infestação de ervas e especiarias. SEMINÁRIO ERVAS E ESPECIARIAS, 2004, São Paulo. Resumos, v. 01 supl.; 2004. 